\title{
Can Higher-Order Risks Explain the Credit Spread Puzzle?
}

\author{
Cédric Okou, Olfa Maalaoui Chun, Georges Dionne, Jingyuan Li*
}

May 11, 2016

(Preliminary)

\begin{abstract}
We tweak the conventional Merton model to account for the asymmetric properties of assets returns and investors asymmetric behavior toward the upside potential of gain versus the downside risk of loss. Using an asymmetric split normal distribution, we capture empirical asymmetries in the underlying return distribution, while we conserve the attractiveness of delivering closed-form pricing formulas that collapse to the basic Merton model in the symmetric Gaussian case. The asymmetric specification outperforms the symmetric one in matching high levels of historical credit spreads. We then link the residual (non-default-model-implied) spread to two illiquidity risk factors. The first factor is extracted from several measures of idiosyncratic illiquidity variables and the second factor is a systematic factor obtained from a general index common to all studied bonds. Our model explains $70 \%$ of the BBB-AAA spread and more than $72 \%$ of $\mathrm{BBB}$ and AAA credit spreads relative to the on-the-run Treasury rates.
\end{abstract}

Keywords: Credit spread puzzle, Asymmetry, Illiquidity, Higher-order risks.

JEL classification: D51; D80; G12

\footnotetext{
*Okou: University of Quebec at Montreal, okou.cedric@uqam.ca. Maalaoui Chun: KAIST, olfa.maalaoui@gmail.com. Dionne: HEC Montréal, georges.dionne@hec.ca. Li: Lingnan University, jingyuanli@ln.edu.hk. The authors gratefully acknowledge financial support from the Institut de la Finance Structurée et des Instruments Dérivés de Montréal (IFSID), the Dauphine-Amundi Chair in Asset Management, the Canada Research Chair in Risk Management, and the Labex Louis Bachelier (ANR 11-LABX-0019).
} 


\section{Introduction}

Credit spreads reward investments on bond markets, and therefore, reflect the various risk compensations shaping the conditional distributions of corporate bond yields. Several modelling frameworks have been proposed to explain the observed historical time variation in corporate credit spreads. Most of these models, while theoretically grounded, have delivered weak to average degrees of empirical success. The discrepancy between model-implied bond spreads and their corresponding historical levels is commonly referred to as the credit spread puzzle (Collin-Dufresne, Goldstein, and Martin, 2001; Elton, Gruber, Agrawal, and Mann, 2001; Huang and Huang, 2012; among others). This puzzle may reflect the fact that distributional assumptions in many credit spread models are not flexible enough to explicitly account for higher-order distributional properties, for instance asymmetric patterns. Moreover, there is a strong evidence that investors' preferences induce asymmetric responses toward upside potential of gains versus downside risk of losses. Credit valuation models often ignore higher-order risks and corresponding higher-order risk attitudes, which if they are priced, may have significant impacts on corporate bond prices. Obviously, accounting for these dimensions could provide a better understanding of the credit spread puzzle.

We tackle this challenge, first by characterizing the importance of higher-order risks in explaining the observed credit spreads. Our goal is to capture the premium due to risks of an order higher than the conventional volatility. To fulfill this objective, we borrow from the literature linking the credit spread puzzle to the equity premium puzzle. Specifically, as in Chen et al (2009) we assume that bondholders are exposed to the same source of risk as the equity holders, using the argument that equities and bonds of a particular firm are affected by the same systematic risk factors given that both assets are contingent claims to the same firm value.

Next, we tweak the Merton (1974) model version in Chen et al (2009) by embedding a split normal asymmetric underlying distribution instead of the Gaussian symmetric distribution. This specification is intended to provide a flexible distributional framework nesting standard benchmarks and introduces asymmetry in returns and unit risk premia. We demonstrate that our setting is a generalization of the standard Merton model by deriving closed-form solutions that collapse to well-known formulas in the symmetric case. We then analyze the ability of both specifications to generate realistic credit spreads. Throughout the paper we will refer to the split normal-based specification as the asymmetric model and to the Gaussian-based specification as the symmetric model. 
Finally, we try to explain the remaining spread (the non-default part of our model-implied spread) by inquiring into the contentious role of liquidity risk in widening total corporate bond spreads during the recent financial crisis. Dick-Nielsen, Feldhütter, and Lando (2012) analyzed the dynamic of bond spreads around the subprime crisis and found that the liquidity component increased significantly during the crisis for all bonds except for AAA bonds. Namely, for BBB bonds this liquidity component increased from 5 basis points (bp) before the crisis to 93 bp during the crisis. Their model does not explicitly account for the effect of systematic liquidity which may have also altered the level of AAA-Treasury spreads. In addition, the effect of the bond level liquidity on the AAA bonds is by construction insignificant. In particular, these authors define the bond illiquidity premium as a spread relative to the premium of benchmark bonds ranked in the lowest 5 th percentile by their illiquidity factor. This benchmark is very likely to be heavily loading on AAA bonds. In recent empirical studies, the effect of systematic component of liquidity risk on bond spreads has not been studied in details. Our approach to solve the bond spread decomposition challenge addresses this gap. We consider idiosyncratic illiquidity factors constructed using bond level liquidity variables, as documented in Dick-Nielsen, Feldhütter, and Lando (2012). We then introduce a systematic measure of illiquidity by constructing a more general index measuring illiquidity for the full universe of corporate bonds, that is, covering bonds rated from AAA to BB. For recent developments on liquidity risk, see Bao, Pan and Wang (2010), and Friewald, Jankowitsch and Subrahmanyam (2012), among others.

Our key contributions to the existing literature are two-fold. First, we show both theoretically and empirically that asymmetrical attitudes towards risk matter in matching observable historical default spreads. To compare our results with the existing work by Chen et al. (2009), we initially consider the same period of 1974-1998. Using the asymmetric split normal distribution model, we obtain a $43.53 \%$ increase in the 4 -year BBB-AAA default spread (78.8 bp) as compared to the symmetric Gaussian specification (54.9 bp). For BBB-AAA total spread, the asymmetric split normal model explains $72.29 \%$ (of the $109 \mathrm{bp}$ ) relative to $50.36 \%$ for the symmetric case. We also use the 10-year maturity bonds and we obtain similar results. Altogether, the asymmetric specification generates a spread that is on average much higher than the spread induced by the symmetric specification. We extend our test to the full universe of bonds traded in the secondary market and available from TRACE database, which covers nearly all corporate bond trading activities. Our new sample period ranges from January 2008 to December 2014. For this period, the asymmetric model explains 58 bp of the historical 4-year BBB-AAA spread (157 bp) while the symmetric model 
explains only $39 \mathrm{bp}$ of the historical spread. ${ }^{1}$

Second, we take advantage from bond level trading data and refine our analysis by focusing on the non-default spread component, which helps us distinguish periods with elevated liquidity disruption risk and periods with high default risk. For instance, our model generates credit spreads that spike especially during the 2008-2009 financial crisis. Our results clearly indicate that default risk is not the major driver of credit spreads during that episode. These findings also reveal that the liquidity risk component of the bond spread is substantial during the crisis and remains relatively significant afterwards. Using the Merton asymmetric default model along with trading based liquidity indexes, we are able to better-match observed historical bond spreads. We explain $70 \%$ of the BBB-AAA spread. This improvement is not only due to the change in the level of BBB-Treasury spread, but also pertains to the change in the level of the AAA-Treasury spread. For instance, relative to the on-the-run Treasury rates we explain $72 \%$ of the BBB-Treasury spread and $77 \%$ of the AAA-Treasury spread. This evidence differs from the findings in Dick-Nielsen, Feldhütter, and Lando (2012) and suggests that AAA bonds are also affected by changes in liquidity risk in our period of analysis, yet most importantly, by the systematic part of it.

The rest of the paper is organized as follows. Section 2 reviews the recent literature on credit risk with an emphasis on the recent contributions regarding liquidity risk. Section 3 presents the asymmetric- Merton default model. Section 4 documents the empirical performance of asymmetric and symmetric credit default models in matching observed credit spreads. Results are provided for the Chen et al.'s (2009) study period ranging from 1974 to 1998 and for the most recent period ranging from 2008 to 2014. Section 5 documents the construction of the idiosyncratic and systematic illiquidity factors and examines their contribution in explaining the residual nondefault credit spreads. Section 6 concludes. Appendix A delineates the equilibrium framework that explicitly characterizes the role of higher-order risks and higher-order risk attitudes in explaining credit spreads. It also provides details on how higher-order risks and higher-order risk behaviors (see for instance Kimball, 1990 and Modica and Scarsini, 2005) such as prudence and aversion towards downside risk are used to price risky assets specifically corporate bonds and corporate bond spreads and to address the credit spread puzzle. Appendix B presents the principal component analysis results used to construct our illiquidity factors.

\footnotetext{
${ }^{1}$ We should emphasize that default probabilities are much lower during this second period than during the 19741998 period.
} 


\section{Literature review on yield spread decomposition}

Before the 2000s, credit risk was considered as synonym to default risk. Yet, research has shown that credit risk cannot only be explained by historical default related variables.

Several structural models try to explain the default premium, which only represents a fraction of the total corporate yield spread. Recent developments in the structural modelling of credit spread suggest the inclusion of additional factors. This new strand of the literature has been able to explain around $25 \%$ to $50 \%$ of the yield spread, depending on the bond rating, the observation period, the nature of the available data, and the set of factors under consideration, such as the business cycle (Elton et al., 2001, Colin-Dufresne et al., 2001, Huang and Huang, 2003, Longstaff, Mithal, and Neis, 2005). The empirical challenge faced by existing models in matching observed corporate yield spreads is labeled as the credit risk puzzle. In their attempt to solving this puzzle, Chen et al. (2008) argue that default rates and Sharpe ratios share a positive correlation, as they both rise during recessions and are low during booms. However, neither do they account for the asymmetry in the underlying return dynamics (Ang and Chen, 2002, Ang and Bekaert, 2002) nor do they consider other risk factors beyond default (Schwarz 2015) to explain the spread. Their model can explain the default BBB-AAA spread, but not the credit BBB-Treasury spread. Therefore, they offer a satisfactory channel to understand the default risk puzzle, but they do not fully explain the credit risk puzzle.

Interestingly, liquidity risk is documented as one of the most important determinants of corporate bond credit spreads. The global financial crisis stemmed from the US subprime mortgage market in 2006-2007, but has spread to virtually every financial markets around the world. The most important aspect of this crisis is the deterioration rate of liquidity provision and credit conditions for several asset classes. Structured financial products such as Asset-backed Commercial Paper (ABCP), Collateralized Debt Obligations (CDO), Corporate Bonds, and even Credit Default

Swaps (CDS) became highly illiquid supporting the idea that illiquidity risk is also an important driver of the credit market.

While clearly both illiquidity and default risks are key determinants of asset prices, it remains important to quantify their relative effects. It is also relevant to ask if there are interactions between these factors, and whether these relations changed substantially in magnitude and quality for preand post-crisis periods. Early contributions on decomposing credit spreads have been limited by the availability of bond data. Detailed data on high frequency bond transactions in the US are 
now available in TRACE starting from 2004. Longstaff, Mithal, and Neis (henceforth LMN, 2005) use information on credit default swaps to disentangle the relative contributions of default and non-default components in corporate yield spreads. Their analysis relies on the assumption that the CDS premium is an appropriate measure of default risk because it is not affected by liquidity risk. LMN (2005) find that a large percentage of corporate yield spread is due to default risk. This result holds for all studied rating categories and is robust to the definition of the riskless curve. In particular, using credit spreads over Treasury yields, the default component attracts on average $51 \%$ of the yield spread. It is important to emphasize that their study period ends before the latest financial crisis. Furthermore, LMN (2005) find a significant non-default component for all firms in theie sample. This non-default spread ranges from about 20 to 100 basis points. They document that the time variation in the non-default corporate bond spread is strongly related to the dynamics of bond-specific illiquidity measures such as the bid/ask spread and the principal amount outstanding of corporate bonds.

There is now a growing literature arguing that traditional illiquidity measures of liquidity, do not capture all liquidity effects, and that well-known measures of credit risk may reflect more than just default risk. These biases can lead to an underestimation of liquidity effects and an overestimation of default effects, especially in times of crisis. Intuitively, investors prefer to hold higher yielding bonds only if they represent compensation for poor liquidity and high default risk. Thus, the default-versus-liquidity decomposition is clearly important. Many authors proxy pure default risk with CDS spread. Nonetheless, these spreads did not necessary isolate default risk during the financial crisis and may have been associated to CDS liquidity risk and issuer solvency risk. For instance, wide and volatile interest rate spreads were observed in the 2007-2009 financial crisis. To identify the relative contribution of default and liquidity components in interest rate spreads, Schwarz (2015) proposes new measures of market illiquidity and interbank credit risk. The author finds that market illiquidity accounts for a sizeable fraction of credit spreads. Moreover, interbank bond spreads are three times more sensitive to liquidity risk than credit risk.

As discussed by Friewald, Jankowitsch and Subrahmanyam (2012), corporate bond markets are less liquid than equity markets, since only a very small proportion of the universe of corporate bonds trades even as often as once a day. In addition, since corporate bonds commonly trade in OTC markets, there is no central market place. Hence, conventional transaction metrics of liquidity do not have the same meaning in these venues, as compared to exchange traded markets. Edwards, Harris, and Piwowar (2007) investigate the properties of the bid-ask spread. Although the 
bid/ask spread is a direct and potentially important illiquidity indicator, it does not fully capture many important aspects of liquidity, such as market depth and resilience (Bao, Pan, and Wang, 2011). Using TRACE data, Friewald, Jankowitsch and Subrahmanyam (2012) and Dick-Nielsen, Feldhütter and Lando (henceforth DFL, 2012) combine several illiquidity proxies to better-account for the different dimensions of the liquidity risk. Bao, Pan, and Wang (2011) also exploit TRACE data to construct a variant of the Roll measure of illiquidity.

We now focus our discussion on the salient findings of a few papers. Friewald, Jankowitsch, and Subrahmanyam (2012) investigate whether liquidity is an important price factor in the US corporate bond market. In particular, they focus on whether liquidity effects are more important in periods of financial crises (the GM/Ford crisis and the subprime crisis, both before the 2007-2008 financial crisis) especially for bonds with high default risk. The main focus of their research is to determine the quantitative impact of liquidity factors, while controlling for default risk, based on credit ratings and other risk characteristics. They use the yield spread of a corporate bond, defined as its yield differential relative to that of a risk-free benchmark of similar duration. The benchmark could be either the Treasury bond or the swap rate curve. Their data cover more than 20,000 bonds, between October 2004 and December 2008. They employ a wide range of liquidity measures such as observable trading activity variables and several alternative liquidity measures such as the Amihud, Roll, zero-return, and price dispersion measure. They also employ market valuations from Markit, bond characteristics from Bloomberg and credit ratings from Standard \& Poor's. They find that liquidity effects account for approximately $14 \%$ of the explained market-wide corporate yield spread changes. While the trading activity variables are important in explaining the bond yield spread changes, the liquidity measures exhibit even stronger effects in terms of economic impact. In particular, measures of trading costs based on transaction data show the strongest effects. They conclude that the economic impact of the liquidity measures is significantly larger in periods of crisis, particularly for speculative grade bonds. But their period of analysis ends in 2008.

DFL show how the increase in corporate bond spreads during the subprime crisis can be attributed to escalating bond illiquidity. They performed a principal component analysis over eight liquidity risk proxies that combine pure price effects and quantity-price effects. They retained the first factor as a measure of illiquidity. This factor is an equally weighted sum of four liquidity variables normalized to a common scale. The four illiquidity variables are measured quarterly and include the Amihuds measure of price quantity impact, a price measure of roundtrip cost of trading and the variability of the two measures. To analyze variations in credit spreads they con- 
sider different control variables such as default risk, taxes, and the general economic environment. They did not use CDSs sold on these bonds to measure default risk. Their main conclusion is that liquidity risk became very important after the subprime crisis especially for investment grade bonds. For speculative grade bonds, the total spread explained by liquidity risk was $24 \%$ during the pre-subprime period and $23 \%$ during the post-subprime crisis. For investment grade bonds, the ratio increased significantly between the two periods ranging from $3 \%$ to $8 \%$ during the presubprime period (according to the ratings) to $23 \%$ to $42 \%$ during the post-subprime crisis. DFL also looked at the effect of the nature of the bond underwriter and the industry origin on bond illiquidity. Specifically, they analyzed the illiquidity of bonds underwritten by Bear Stearns and Lehman Brothers and compared them with the illiquidity of bonds underwritten by other banks. They found a small effect for Bear Stearns, which was acquired by J.P.Morgan. However, they document a big jump in the illiquidity index of bonds underwritten by Lehman Brothers during the period around the default of the bank followed by some persistence after the bankruptcy date (September 15, 2008). By comparing the illiquidity index of bonds of industrial firms with the index of bonds of financial firms, they find that bonds of financial firms were more liquid before the onset of the financial crisis in July 2007 and became less liquid after that date. In conclusion, these authors observed that bond spreads increased considerably during the financial crisis and found that bond illiquidity contributed significantly to that widening.

Bao, Pan, and Wang (2011) examine the liquidity of corporate bonds and its asset-pricing implications using an empirical measure of illiquidity based on the magnitude of transitory price movements. In their measure, illiquidity arises from market frictions, such as costs and constraints for trading and capital flows, and its impact to the market is transitory. Relying on transactionlevel data for a broad cross-section of corporate bonds from 2003 through 2008, they find the illiquidity in corporate bonds to be significant, substantially greater than what can be explained by bid-ask bounce, and closely linked to liquidity-related bond characteristics. More importantly, they find a strong commonality in the time variation of bond illiquidity, which rises sharply during market crises and reaches a high in 2008 during the credit market turmoil. They conclude that the effects of liquidity during the recent financial crisis actually dominate those of default risk. They construct their empirical measure of illiquidity by extracting the transitory component in the price movement of corporate bonds. Their measure of illiquidity is a variant of Roll measure. Roll's model transitory price movements arise purely from bid-ask bounce. Here the authors assume that directions of trades are serially dependent. For a given bid-ask spread, positive serial correlation 
in trade directions, which could be the case when liquidity is lacking and traders break up their trades, tends to increase the implied bid-ask spreads. In other words the lack of liquidity in an asset may rise to transitory components in its prices. Since transitory price movements lead to negatively serially correlated price changes, the negative of the autocovariance in price changes provides a simple empirical measure of illiquidity. So their model captures a broader impact of illiquidity on prices, beyond the effect of bid-ask spread, and it does so without relying on specific bond pricing models. They find important implications of illiquidity on bond yield spreads. They find a strong positive relation between their illiquidity measure and the age of a bond. Bonds with smaller issuance tend to have higher illiquidity and the same is true for bonds with higher idiosyncratic return volatility and smaller average trade sizes. When they aggregate their illiquidity measure across bonds to examine its time-series properties, they obtain strong commonality in bond illiquidity that is closely related to market conditions, especially during credit-market crises. This implies that an important portion of their estimated bond market illiquidity is not contained just in the bond market. Finally, they obtain that their illiquidity measure can explain up to 84 basis points in the yield spread. They conclude that the negative autocovariance in price changes observed in the bond market is much more substantial than merely the bid-ask effect. Our measure of illiquidity captures more broadly the impact of illiquidity in the market.

Chen et al. (2015) develop a structural credit risk model to examine how the interactions between liquidity and default affect corporate bond pricing. The model captures realistic time variation in default risk premium and the default-liquidity spiral over the business cycle. The authors simultaneously match the average default probabilities, credit spreads, and bid-ask spreads observed in the data. A structural decomposition reveals that the default-liquidity dependence account for 10 to $24 \%$ of the observed credit spreads. Up to now, the theoretical literature on structural credit risk modeling has almost exclusively focused on the default component of credit spreads. The credit spread puzzle refers to the finding that, after matching the observed default and recovery rates, traditional structural models produce credit spreads for investment grade bonds that are significantly lower than those in the data. These models do not consider liquidity risk. This paper introduces liquidity risk into a model with macroeconomic fluctuations (Chen, 2010). The authors propose a joint modeling of default and liquidity risk over the business cycle. Such interactions give rise to endogenous default as well as endogenous liquidity, which helps to explain why corporate bonds with higher credit ratings tend to be more liquid and why corporate bonds are less liquid during economic downturns. In the model, investors face uninsurable idiosyncratic 
liquidity shocks, which increases their costs of holding corporate bonds. Market illiquidity arises endogenously when investors have to search for dealers to intermediate transactions with other investors not yet hit by liquidity shocks. In the meantime they incur costs of having to hold onto the bonds. Moreover default risk affects the liquidity discount of corporate bonds. Heavier liquidity discounts make it more costly for firms to refinance/roll-over their maturing debt, hence raising the probability of default. Thus, a default-liquidity spiral arises: when secondary market liquidity deteriorates, equity holders are more likely to default, which in turn worsens secondary bond market liquidity even further. The calibration focuses predominantly on bonds with a 10year maturity although they authors also investigate 5-year maturity bonds. Usually models in the finance literature consider default risk and liquidity risk as independent. The actual model is much more general and considers that both liquidity and default are linked. To quantify the interaction between default and liquidity, they propose a structural decomposition of credit spreads that nests the common additive default-liquidity decomposition. As in Longstaff et al. (2015) they first identify the default component in the total credit spreads of a corporate bond by pricing the same bond in a perfectly liquid market but using the default threshold endogenously derived from the full model with liquidity frictions. After subtracting this default component, they identify the remaining credit spread as the liquidity component. In fact they have four components in the credit spread: a pure default component, a pure illiquidity component, a liquidity-driven default component, and default-driven illiquidity component. With the 10-year maturity, they find that the interaction terms account for about $10 \%$ of the total credit spread of AAA/Aa rated bonds and up to $24 \%$ of the total spread of BB rated bonds across the two aggregate states. Overall for BBB-rated bonds, their model gives a satisfactory match for 10-year credit spreads: in good state, the model predicts 182 bps while the data has 150 bps; in bad state, they have 261 bps in the model versus 262 bps in the data. The match of default probabilities for BBB-rated bonds is also good: the model predicts a 10-year cumulative default probability of $7.9 \%$ while it is $7 \%$ in the data. They also have good results for AAA/AA bonds. The results are less satisfactory for 5-year maturity.

\section{Model}

We extend Merton's (1974) bond pricing model to explicitly account for the asymmetry in the underlying distribution. We refer to the benchmark specification as the symmetric model whereas the new specification is termed as the asymmetric model. 


\subsection{Asymmetric distribution for bond pricing}

To highlight the role asymmetry in the pricing of risky bonds, we use the split normal distribution introduced by Gibbons and Mylroie (1973) to model random changes in the firm value over time. We choose this distribution as it can accommodate empirically plausible values of asymmetry - a key feature in our analysis -, nests the standard Gaussian distribution, and is analytically tractable. See John (1982) for details. Recently, the split normal distribution has been successfully employed by Feunou et al. (2013) to model downside equity market volatility.

Denote by $\mathbb{I}_{[\bullet]}$ an indicator function which takes values equal to either one or zero, depending on whether the target condition is met or not. The density function of a split normal random variable is given by

$$
\operatorname{sn}\left(z ; m, \sigma_{d}, \sigma_{u}\right)=C\left(\exp \left(-\frac{1}{2}\left(\frac{z-m}{\sigma_{d}}\right)^{2}\right) \mathbb{I}_{[z \leq m]}+\exp \left(-\frac{1}{2}\left(\frac{z-m}{\sigma_{u}}\right)^{2}\right) \mathbb{I}_{[z>m]}\right),
$$

where $m$ is the mode, $C=\sqrt{2 / \pi}\left(\sigma_{d}+\sigma_{u}\right)^{-1}$ is a normalizing constant, $\sigma_{d}>0$ and $\sigma_{u}>0$ are the left (down) and right (up) hand side standard deviations, respectively. Specifically, up to a constant term, $\sigma_{d}=\sqrt{(1-2 / \pi)^{-1} \operatorname{var}(Z \mid Z \leq m)}$ is the standard deviation conditional on $z$ being less than the mode (downside standard deviation), whereas $\sigma_{u}=\sqrt{(1-2 / \pi)^{-1} \operatorname{var}(Z \mid Z>m)}$ is the standard deviation conditional on $z$ being greater than the mode (upside standard deviation). It is obvious that the split normal distribution is flexible enough to accommodate various levels of asymmetry. Actually, if $\sigma_{d}>\sigma_{u}$ the split normal distribution is left-skewed - fatter left tail and slimmer right tail than standard normal - and the "balance of risk", $\operatorname{Pr}(Z \leq m)=\frac{\sigma_{d}}{\sigma_{d}+\sigma_{u}}$, is greater that 0.5. Equivalently, when $\sigma_{d}<\sigma_{u}$ we obtain the opposite feature, that is, slimmer left tail and fatter right tail than standard normal. Finally, if $\sigma_{d}=\sigma_{u}$ the split normal density reduces to the standard - symmetric - normal which exhibits "balanced downside and upside risks".

Alternative parameterizations of the split normal distribution are discussed in Johnson et al. (1994) and Britton et al. (1998). For instance, the split normal distribution can be parameterized in terms of a mean $E(Z)=\mu$, a variance $\operatorname{var}(Z)=\sigma^{2}$ and a normalized skew parameter termed as Pearson mode skewness $s=(\mu-m) / \sigma$. The functional relationships between these new parameters and the initial ones are as follows

$$
\begin{aligned}
\sigma^{2} & =(1-2 / \pi)\left(\sigma_{u}-\sigma_{d}\right)^{2}+\sigma_{d} \sigma_{u}, \\
s & =\sqrt{2 / \pi}\left(\sigma_{u}-\sigma_{d}\right) / \sigma \\
\mu & =m+\sigma s=m+\sqrt{2 / \pi}\left(\sigma_{u}-\sigma_{d}\right) .
\end{aligned}
$$


Clearly, the distribution is skewed to the left for $s<0$, that is when $\sigma_{d}>\sigma_{u}$. A right-skewed distribution is induced by $s>0$ or $\sigma_{d}<\sigma_{u}$. If $\sigma_{d}=\sigma_{u}$ then $s=0$ and the distribution boils down to the - symmetric - normal distribution.

Note that the third standardized central moment measure of skewness $\left(s k=E\left(\left(\frac{Z-\mu}{\sigma}\right)^{3}\right)\right)$ is related to the Pearson mode skewness $(s)$ according to

$$
s k=s\left(1-(\pi-3) s^{2}\right) .
$$

Figure 1 shows three split normal densities for

$$
\begin{gathered}
\left(m=0, \sigma_{d}=1, \sigma_{u}=1\right) \Leftrightarrow(m=0, \sigma=1, s=0)-\text { standard normal }- \\
\left(m=1, \sigma_{d}=\frac{\left(\sqrt{8-\frac{3 \pi}{2}}+\sqrt{\frac{\pi}{2}}\right)}{2}, \sigma_{u}=\sigma_{d}-\sqrt{\frac{\pi}{2}}\right) \Leftrightarrow(m=1, \sigma=1, s=-1)-\text { left skew }- \\
\left(m=-1, \sigma_{d}=\frac{\left(\sqrt{8-\frac{3 \pi}{2}}-\sqrt{\frac{\pi}{2}}\right)}{2}, \sigma_{u}=\sigma_{d}+\sqrt{\frac{\pi}{2}}\right) \Leftrightarrow(m=-1, \sigma=1, s=1)-\text { right skew - . }
\end{gathered}
$$

This asymmetric property of the split normal distribution is at the heart of our analysis which aims at distinguishing the downside risk of loss from the upside potential of gains in the pricing of a risky bond.

From the density formula, it follows that the cumulative distribution $\operatorname{Pr}(Z \leq z)$ of a split normal random variable is

$$
S N\left(z ; m, \sigma_{d}, \sigma_{u}\right)=C \sqrt{2 \pi} \sigma_{d} \Phi\left(\frac{z-m}{\sigma_{d}}\right) \mathbb{I}_{[z \leq m]}+\left[1-C \sqrt{2 \pi} \sigma_{u}\left(1-\Phi\left(\frac{z-m}{\sigma_{u}}\right)\right)\right] \mathbb{I}_{[z>m]}
$$

where $\Phi(\bullet)$ is the cumulative standard normal distribution. Hence, the $\alpha$-quantile of a split normal distribution may be calculated as

$$
S N_{m, \sigma_{d}, \sigma_{u}}^{-1}(\alpha)=m+\sigma_{d} \Phi^{-1}\left(\frac{\alpha}{C \sqrt{2 \pi} \sigma_{d}}\right) \mathbb{I}_{\left[\alpha \leq \frac{\sigma_{d}}{\sigma_{d}+\sigma_{u}}\right]}+\sigma_{u} \Phi^{-1}\left(\frac{\alpha+C \sqrt{2 \pi} \sigma_{u}-1}{C \sqrt{2 \pi} \sigma_{u}}\right) \mathbb{I}_{\left[\alpha>\frac{\sigma_{d}}{\sigma_{d}+\sigma_{u}}\right]},
$$

where $\frac{\sigma_{d}}{\sigma_{d}+\sigma_{u}}$ is the probability of the split normal variable being less than the mode.

\subsection{Pricing formula}

The cash flows at maturity $\mathrm{T}$ of a zero-coupon risky bond are

$$
\begin{aligned}
\$ 1 \text { if } V(T) & >D \\
\$(1-L) & \text { if } V(T)<D
\end{aligned}
$$


Figure 1: Standard Normal, Left-Skewed and Right-Skewed Split Normals

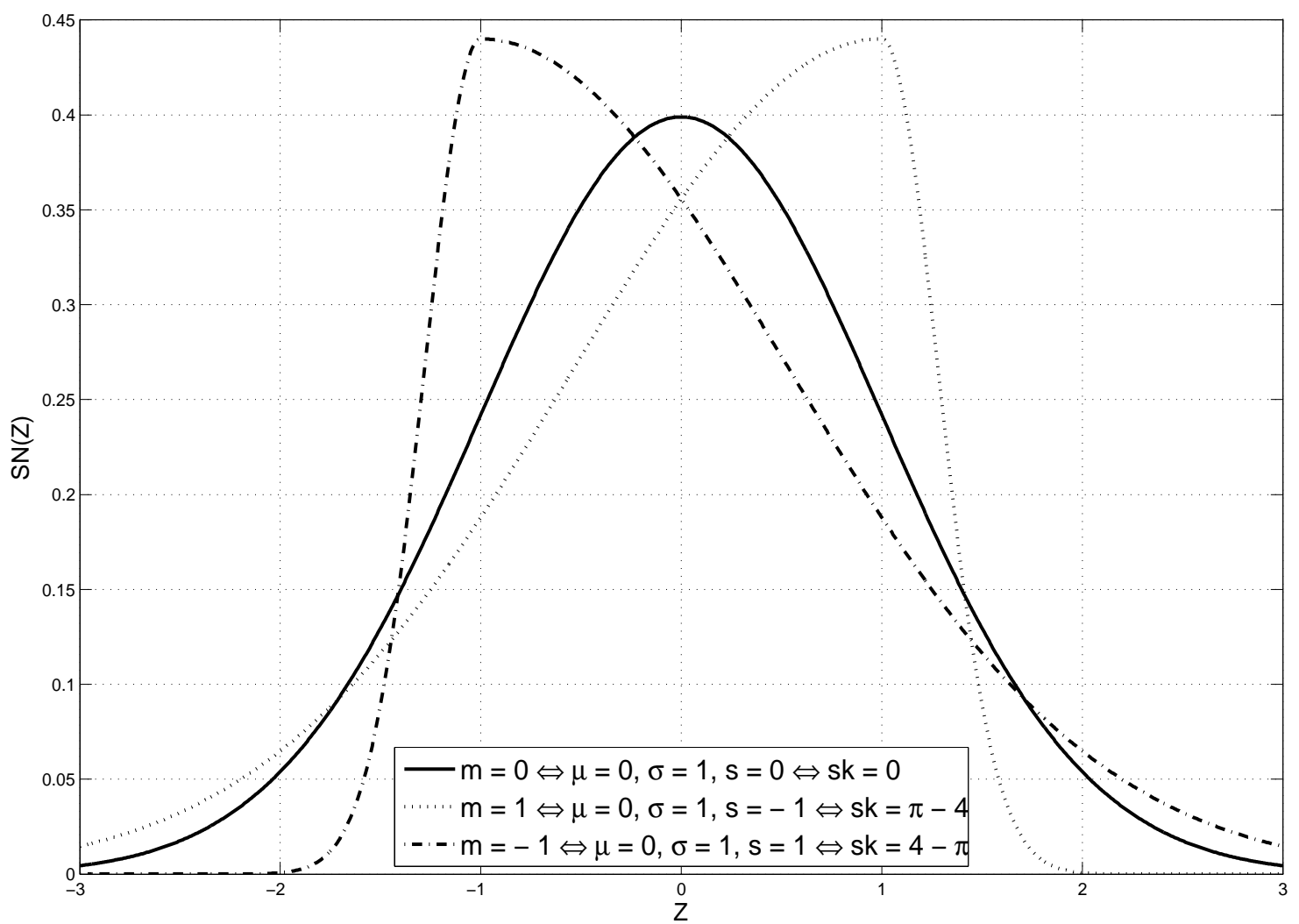

This figure presents the standard normal (solid line), left-skewed (dotted line) and right-skewed (dash-dotted line) split normal densities for different sets of parameters. 
where $D$ is the default boundary, that is, the zero-coupon risky bond defaults only at maturity $\mathrm{T}$ if the firm value at maturity $V(T)$ falls below $D$ (Merton 1974). ${ }^{2}$ The loss given default $L$ measures various default costs. When default occurs, bondholders receive a constant fraction of the payoff $(1-L)$, also defined as recovery rate.

For simplicity, we consider the time-T cash flow to boundary log-ratio which is defined as

$$
v(T)=\log \left(\frac{V(T)}{D}\right) .
$$

The corresponding stochastic process $v(t)$ is defined over a physical probability space characterized by $(\Omega, \mathbb{P}, \mathcal{F})$, where $\left\{\mathcal{F}_{t}\right\}_{t=0}^{\infty} \in \mathcal{F}$ are progressive filters on $\mathcal{F}$. Girsanov's change of measure formula $\left.\frac{d \mathbb{Q}}{d \mathbb{P}}\right|_{\mathcal{F}_{T}}=Z_{T}, T<\infty$ allows to relate the risk neutral probability measure $\mathbb{Q}$ to the physical measure $\mathbb{P}$. Under both measures, the dynamics of $v(t)$ are

$$
\begin{aligned}
& d v(t)=\left(\mu-\delta-\frac{\sigma^{2}}{2}\right) d t+d Z^{\mathbb{P}}, \\
& d v(t)=\left(r_{f}-\delta-\frac{\sigma^{2}}{2}\right) d t+d Z^{\mathbb{Q}},
\end{aligned}
$$

where $\mu$ is the expected return, $\delta$ is the dividend yield and $r_{f}$ is the risk-free rate. We further assume that $d Z^{\mathbb{P}}$ and $d Z^{\mathbb{Q}}$, respectively under the $\mathbb{P}$ and $\mathbb{Q}$ probability measures, follow a zeromean split normal distribution $s n\left(m=-\sqrt{2 / \pi}\left(\sigma_{u}-\sigma_{d}\right) \sqrt{T}, \sigma_{d} \sqrt{T}, \sigma_{u} \sqrt{T}\right)$ with a mode $(m)$, a downside volatility $\left(\sigma_{d} \sqrt{T}\right)$ and an upside volatility $\left(\sigma_{u} \sqrt{T}\right)$. All parameters in Equations (8) and (9) are constant. One can easily check that this split normal distribution is centered around its mean $\mu=m+\sqrt{2 / \pi}\left(\sigma_{u}-\sigma_{d}\right) \sqrt{T}=0$. This specification nests the benchmark model of Merton (1974), which is obtained by setting $\sigma_{d}=\sigma_{u}=\sigma$. It follows that

$$
\begin{aligned}
v(T) \mid v(0) & \sim S N_{\mathbb{P}}\left(m_{v}^{\mathbb{P}}, \sigma_{d}^{2} T, \sigma_{u}^{2} T\right) \\
& \sim S N_{\mathbb{Q}}\left(m_{v}^{\mathbb{Q}}, \sigma_{d}^{2} T, \sigma_{u}^{2} T\right)
\end{aligned}
$$

where $\sigma^{2}=(1-2 / \pi)\left(\sigma_{u}-\sigma_{d}\right)^{2}+\sigma_{d} \sigma_{u}, m_{v}^{\mathbb{P}}=v(0)+\left(\mu-\delta-\frac{\sigma^{2}}{2}\right) T-\sqrt{2 / \pi}\left(\sigma_{u}-\sigma_{d}\right) \sqrt{T}$, $m_{v}^{\mathbb{Q}}=v(0)+\left(r_{f}-\delta-\frac{\sigma^{2}}{2}\right) T-\sqrt{2 / \pi}\left(\sigma_{u}-\sigma_{d}\right) \sqrt{T}$, and $S N(\bullet)$ is the cumulative split normal distribution. Thus, the expected firm value at maturity under the physical measure $\left(\mu_{v}^{\mathbb{P}}\right)$ is $E_{\mathbb{P}}(v(T))=$ $v(0)+\left(\mu-\delta-\frac{\sigma^{2}}{2}\right) T$ and its risk-neutral counterpart $\left(\mu_{v}^{\mathbb{Q}}\right)$ is $E_{\mathbb{Q}}(v(T))=v(0)+\left(r_{f}-\delta-\frac{\sigma^{2}}{2}\right) T$ or $\mu_{v}^{\mathbb{P}}-\theta \sigma T$, where $\theta=\left(\mu-r_{f}\right) / \sigma$ stands for the Sharpe ratio.

\footnotetext{
${ }^{2}$ The default boundary $D$ is set to the face value of debt in the standard setup of Merton (1974) model. Subsequent studies by Leland (2004) and Davidenko (2006) argue that the default boundary is a portion (70\% to $75 \%)$ of the face value of debt.
} 
The cumulative density function $\operatorname{Pr}\left(v(T) \leq v^{*}\right)$ under the $\mathbb{P}$-measure is

$$
\begin{aligned}
S N_{\mathbb{P}}\left(v^{*} ; m_{v}^{\mathbb{P}}, \sigma_{d} \sqrt{T}, \sigma_{u} \sqrt{T}\right) & =C_{v} \sqrt{2 \pi} \sigma_{d} \sqrt{T} \Phi\left(\frac{v^{*}-m_{v}^{\mathbb{P}}}{\sigma_{d} \sqrt{T}}\right) \mathbb{I}_{\left[v^{*} \leq m_{v}^{\mathbb{P}}\right]} \\
& +\left[1-C_{v} \sqrt{2 \pi} \sigma_{u} \sqrt{T}\left(1-\Phi\left(\frac{v^{*}-m_{v}^{\mathbb{P}}}{\sigma_{u} \sqrt{T}}\right)\right)\right] \mathbb{I}_{\left[v^{*}>m_{v}^{\mathbb{P}}\right]},
\end{aligned}
$$

where $C_{v}=\sqrt{2 / \pi}\left[\left(\sigma_{d}+\sigma_{u}\right) \sqrt{T}\right]^{-1}$ and $\Phi(\bullet)$ is the cumulative standard normal.

Equivalently, the cumulative density function under the $\mathbb{Q}$-measure is

$$
\begin{aligned}
S N_{\mathbb{Q}}\left(v^{*} ; m_{v}^{\mathbb{Q}}, \sigma_{d} \sqrt{T}, \sigma_{u} \sqrt{T}\right) & =C_{v} \sqrt{2 \pi} \sigma_{d} \sqrt{T} \Phi\left(\frac{v^{*}-m_{v}^{\mathbb{Q}}}{\sigma_{d} \sqrt{T}}\right) \mathbb{I}_{\left[v^{*} \leq m_{v}^{\mathbb{Q}}\right]} \\
& +\left[1-C_{v} \sqrt{2 \pi} \sigma_{u} \sqrt{T}\left(1-\Phi\left(\frac{v^{*}-m_{v}^{\mathbb{Q}}}{\sigma_{u} \sqrt{T}}\right)\right)\right] \mathbb{I}_{\left[v^{*}>m_{v}^{\mathbb{Q}}\right]} .
\end{aligned}
$$

There is default at time $T$ if the firm has a negative terminal value for its cash flow to boundary $\log$-ratio process $v(T)<0$.

Thus, the probability of default under the physical measure is

$$
\begin{aligned}
D P^{\mathbb{P}} & =S N_{\mathbb{P}}\left(v^{*}=0 ; m_{v}^{\mathbb{P}}, \sigma_{d} \sqrt{T}, \sigma_{u} \sqrt{T}\right) \\
& =C_{v} \sqrt{2 \pi} \sigma_{d} \sqrt{T} \Phi\left(\frac{-m_{v}^{\mathbb{P}}}{\sigma_{d} \sqrt{T}}\right) \mathbb{I}_{\left[0 \leq m_{v}^{\mathbb{P}}\right]} \\
& +\left[1-C_{v} \sqrt{2 \pi} \sigma_{u} \sqrt{T}\left(1-\Phi\left(\frac{-m_{v}^{\mathbb{P}}}{\sigma_{u} \sqrt{T}}\right)\right)\right] \mathbb{I}_{\left[0>m_{v}^{\mathbb{P}}\right]} .
\end{aligned}
$$

Similarly, the probability of default under the risk-neutral measure is

$$
\begin{aligned}
D P^{\mathbb{Q}} & =S N_{\mathbb{Q}}\left(v^{*}=0 ; m_{v}^{\mathbb{Q}}, \sigma_{d} \sqrt{T}, \sigma_{u} \sqrt{T}\right) \\
& =C_{v} \sqrt{2 \pi} \sigma_{d} \sqrt{T} \Phi\left(\frac{-m_{v}^{\mathbb{Q}}}{\sigma_{d} \sqrt{T}}\right) \mathbb{I}_{\left[0 \leq m_{v}^{\mathbb{Q}}\right]} \\
& +\left[1-C_{v} \sqrt{2 \pi} \sigma_{u} \sqrt{T}\left(1-\Phi\left(\frac{-m_{v}^{\mathbb{Q}}}{\sigma_{u} \sqrt{T}}\right)\right)\right] \mathbb{I}_{\left[0>m_{v}^{\mathbb{Q}}\right]} \\
& =C_{v} \sqrt{2 \pi} \sigma_{d} \sqrt{T} \Phi\left(\frac{-m_{v}^{\mathbb{P}}}{\sigma_{d} \sqrt{T}}+\theta_{d} \sqrt{T}\right) \mathbb{I}_{\left[0 \leq m_{v}^{\mathbb{Q}}\right]} \\
& \left.+\left[1-C_{v} \sqrt{2 \pi} \sigma_{u} \sqrt{T}\left(1-\Phi\left(\frac{-m_{v}^{\mathbb{P}}}{\sigma_{u} \sqrt{T}}+\theta_{u} \sqrt{T}\right)\right)\right] \mathbb{I}_{\left[0>m_{v}\right.}{ }^{\mathbb{Q}}\right] \\
& =C_{v} \sqrt{2 \pi} \sigma_{d} \sqrt{T} \Phi\left(\frac{S N_{0}^{-1}\left(D P^{\mathbb{P}}\right)}{\sigma_{d} \sqrt{T}}+\theta_{d} \sqrt{T}\right) \mathbb{I}_{\left[0 \leq m_{v}^{\mathbb{Q}}\right]} \\
+ & {\left[1-C_{v} \sqrt{2 \pi} \sigma_{u} \sqrt{T}\left(1-\Phi\left(\frac{S N_{0}^{-1}\left(D P^{\mathbb{P}}\right)}{\sigma_{u} \sqrt{T}}+\theta_{u} \sqrt{T}\right)\right)\right] \mathbb{I}_{\left[0>m_{v}^{\mathbb{Q}}\right]} }
\end{aligned}
$$


where $S N_{0}^{-1}\left(D P^{\mathbb{P}}\right)=S N_{m=0, \sigma_{d} \sqrt{T}, \sigma_{u} \sqrt{T}}^{-1}\left(D P^{\mathbb{P}}\right)=-m_{v}^{\mathbb{P}}$ is defined as the $D P^{\mathbb{P}}$-quantile of a zeromode split normal with downside and upside standard deviations $\sigma_{d} \sqrt{T}$ and $\sigma_{u} \sqrt{T}$. Accordingly, we define the downside volatility weighted Sharpe ratio as $\theta_{d}=\left(\mu-r_{f}\right) / \sigma_{d}=\left(\sigma / \sigma_{d}\right) \times \theta$ and the upside volatility weighted Sharpe ratio as $\theta_{u}=\left(\mu-r_{f}\right) / \sigma_{u}=\left(\sigma / \sigma_{u}\right) \times \theta$.

When downside and upside standard deviations are equal, that is $\sigma_{d} \sqrt{T}=\sigma_{u} \sqrt{T}=\sigma \sqrt{T}$, the quantile function of the corresponding zero-mode split normal distribution implies

$$
S N_{0}^{-1}\left(D P^{\mathbb{P}}\right)=\sigma \sqrt{T} \Phi^{-1}\left(D P^{\mathbb{P}}\right)
$$

By combining Equations (13) and (14), we find for the symmetric case that

$$
D P^{\mathbb{Q}}=\Phi\left(\Phi^{-1}\left(D P^{\mathbb{P}}\right)+\theta \sqrt{T}\right)
$$

Thus, the risk-neutral default probability formula in Equation (13) nests Merton's (1974) specification which assumes a standard Gaussian distribution.

Recall that the price of a zero-coupon risky bond which pays off in $\mathrm{T}$ periods is computed as

$$
\begin{aligned}
B_{0}^{T} & =e^{-r_{f} T} E_{0}^{\mathbb{Q}}\left(1-\mathbb{I}_{[v(T)<0]} L\right) \\
& =e^{-r_{f} T}\left(1-L \times D P^{\mathbb{Q}}\right)
\end{aligned}
$$

where $L$ is the constant loss given default.

By defining the yield to maturity of a zero-coupon $j$-rated risky bond as

$$
y_{j}=-\frac{1}{T} \log \left(B_{j, 0}^{T}\right)
$$

one can express the credit spread as

$$
y_{j}-r_{f}=-\frac{1}{T} \log \left(1-L \times D P_{j}^{\mathbb{Q}}\right),
$$

where the formula of $D P_{j}^{\mathbb{Q}}$ is given by Equation (13). Similarly, we can define the BBB-AAA default spread as

$$
S P_{B B B-A A A}^{\text {default }}=-\frac{1}{T} \log \left(\frac{1-L \times D P_{B B B}^{\mathbb{Q}}}{1-L \times D P_{A A A}^{\mathbb{Q}}}\right)
$$

\section{Empirical analysis of the asymmetric model}

We now assess the empirical ability of the asymmetric default model to match the historical spreads. 


\subsection{Data and empirics: sample from 1974 to 1998}

We benchmark our study to the work of Chen et al. (2009). We first reproduce their Merton (1974) implied default spreads. We then illustrate the role of asymmetry in the pricing of risky bonds by assuming split normal innovations for the cash flow to boundary log-ratio dynamics. Asymmetry appears to be a key feature in the analysis of higher-order risk behaviors, such as downside risk, for US equity markets (Ang and Chen, 2002), international equity markets (Ang and Bekaert, 2002), government bond markets (Fujiwara et al., 2013), asset allocation (Jondeau and Rockinger, 2006) and consumption-based pricing relationships (Dionne et al., 2013).

To reproduce Chen et al.'s (2009) results, we collect (1974-1998) monthly stock data from CRSP and aggregate them by rating categories. To compute the Sharpe ratio for a typical firm, Chen et al. (2009) use equity returns arguing that, for their sample period, equity data are more reliable and liquid than bond data. We also collect data on 1- and 4-year cumulative default probabilities from Moodys over the same period. According to Moody's 2005 annual report, the 4-year cumulative default rates over 1970-2001 period for BBB and AAA firms are $1.55 \%$ and $0.04 \%$, respectively. Similarly, the estimated 10-year BBB and AAA cumulative default rates are $4.89 \%$ and $0.63 \%$, respectively. Consistent with its historical level during the period of analysis, we use a loss given default rate of $55.1 \%$. Finally, to reproduce an equivalent measure of the historical Moody's BBBAAA total bond spreads publicly provided by the Federal Reserve, we use bonds with similar maturity range from the Warga (1998) fixed income database, as in Dionne et al. (2011). The reason for choosing Warga data source instead of Federal Reserve index is that it allows to specify the sector, the rating category, and the maturity. Our average BBB-AAA spread is $140 \mathrm{bp}$ and is comparable to the avarage Moody's BBB-AAA index spread of $109 \mathrm{bp}$.

We calibrate Merton's model-implied spreads based on the average Sharpe ratio for a typical BBB-rated firm. The Sharpe ratio is defined as the ratio of the firm stock excess return to the stock return volatility. The average excess return over the 1974-1998 sample period is equal to $6.71 \%$. Under the symmetric (gaussian) Merton setting, the volatility estimate is $\sigma_{d}=\sigma_{u}=\sigma=32.08 \%$. The resulting Sharpe ratio of $\theta=6.71 \% / 32.08 \%=0.21$ is consistent with the value used by Chen et al. (2009). By contrast, under the asymmetric Merton setting, the split normal distribution implies a downside volatility $\sigma_{d}=23.04 \%$ that is 1.3 times larger than its upside counterpart $\sigma_{u}=18.02 \%$. The corresponding equity return sample distribution is left-skewed with a Pearson mode skewness $s$ of -0.19 . Moreover, the left-side volatility weighted Sharpe ratio $\theta_{d}=6.71 \% / 23.04 \%=0.29$ is 
smaller than the right-side volatility weighted Sharpe ratio $\theta_{u}=6.71 \% / 18.02 \%=0.37$ because there is more variability in the lower part than in the upper part of the return distribution. This empirical result provides more evidence for the downside risk of loss than the upside potential of gain in equity markets from 1974 to 1998.

Table 1 reports the model implied spreads for various Sharpe ratio values. Panel A gives the results for the Merton asymmetric model and Panel B presents results for the Merton symmetric case. Note that the left-side and right-side Sharpe ratios are both higher in the asymmetric case $\left(\theta_{d}=0.29, \theta_{u}=0.37\right)$ relative to the symmetric case $\left(\theta_{u}=\theta_{d}=\theta=0.21\right)$. Intuitively, the fact that both $\sigma_{d}$ and $\sigma_{u}$ are smaller than $\sigma$ reflects a tighter dispersion in each half-support distribution as compared to the observed variability over the entire support of the empirical distribution.

In this setup, the Sharpe ratio is clearly a key driver of the credit spread variability, since this ratio quantifies the level of risk-return trade-off. As shown in Panel A of Table 1, the bond spread values generated by the symmetric distribution are nearly identical to the empirical findings of Chen et al. (2009) for the Merton (1974) model. Moreover, we find that the asymmetric specification (Panel B) delivers higher BBB-AAA default spreads than the symmetric benchmark model (Panel A). When the parameter values are calibrated to their historical levels, 4-year BBBAAA spreads are about $54.9 \mathrm{bp}$ for the symmetric benchmark model and $78.8 \mathrm{bp}$ for the asymmetric split normal model. Thus, by specifying a flexible asymmetric return distribution, the 4-year modelimplied spread increases by $43.53 \%=(78.8 \mathrm{bp} / 54.9 \mathrm{bp}-1)$. For a maturity of 10 years, we observe an increase of $47.98 \%=(109.2 \mathrm{bp} / 73.8 \mathrm{bp}-1)$ in the calibrated spread when moving from the symmetric to the asymmetric specification. In addition, the asymmetric split normal model yields a BBBAAA spread that is much closer to the historical level. Specifically, the asymmetric split normal model explains $78.00 \%=(109.2 \mathrm{bp} / 140 \mathrm{bp})$ of the 10-year historical BBB-AAA spread relative to $52.71 \%=(73.8 \mathrm{bp} / 140 \mathrm{bp})$ for the symmetric Gaussian model. 
Table 1: Model-implied BBB-AAA spreads for different Sharpe ratios (Jan. 1974 to Dec. 1998)

\begin{tabular}{|c|c|c|c|c|c|}
\hline \multirow[b]{2}{*}{ Sharpe ratio } & \multicolumn{2}{|c|}{ 4-year maturity } & \multicolumn{3}{|c|}{ 10-year maturity } \\
\hline & AAA & BBB-AAA & $\mathrm{BBB}$ & $\mathrm{AAA}$ & BBB-AAA \\
\hline
\end{tabular}

Panel A: Symmetric model $\sigma_{d}=\sigma_{u}=\sigma ; s=0$

$\theta_{d}=\theta_{u}=\theta$

0.15

0.20

$0.21=\theta^{*}$

0.25

0.30

0.35

0.40

\begin{tabular}{lllrrr}
\multicolumn{5}{c}{ Spreads in basis points } \\
\hline 44.0 & 1.6 & 42.5 & 67.7 & 12.1 & 55.7 \\
55.0 & 2.2 & 52.8 & 88.2 & 17.4 & 70.8 \\
57.2 & 2.4 & 54.9 & 92.4 & 18.6 & 73.8 \\
68.1 & 3.0 & 65.1 & 112.8 & 24.7 & 88.2 \\
83.7 & 4.1 & 79.6 & 141.8 & 34.3 & 107.6 \\
102.0 & 5.6 & 96.5 & 175.2 & 46.6 & 128.6 \\
123.4 & 7.4 & 116.0 & 212.9 & 62.2 & 150.8
\end{tabular}

Panel B: Asymmetric model $\sigma_{d}=1.3 \sigma_{u} ; s=-0.19$

$\theta_{d} \quad \theta_{u}=1.3 \theta_{d}$

\begin{tabular}{lccccccc}
0.15 & 0.195 & 44.6 & 1.6 & 43.0 & 69.3 & 12.3 & 57.1 \\
0.20 & 0.260 & 55.9 & 2.2 & 53.7 & 90.9 & 17.8 & 73.1 \\
0.25 & 0.325 & 69.5 & 3.1 & 66.5 & 117.2 & 25.4 & 91.8 \\
$0.29=\theta_{d}^{*}$ & $0.372=\theta_{u}^{*}$ & 82.7 & 4.0 & 78.8 & 142.6 & 33.5 & 109.2 \\
0.30 & 0.390 & 85.8 & 4.2 & 81.6 & 148.5 & 35.5 & 113.0 \\
0.35 & 0.455 & 105.0 & 5.7 & 99.4 & 184.9 & 48.5 & 136.4 \\
0.40 & 0.520 & 127.5 & 7.6 & 119.9 & 226.6 & 65.2 & 161.5 \\
\hline
\end{tabular}

The four-year BBB (AAA) default rate is $1.55 \%(0.04 \%)$. The 10 -year BBB (AAA) default rate is $4.89 \%(0.63 \%)$. The expected loss rate is $55.1 \%$. For the symmetric cash flow distribution with $\sigma_{d}=\sigma_{u}=\sigma$, the downside and upside Sharpe ratios are equal $\theta_{d}=\theta_{u}=\theta$ and the Pearson mode skewness is $s=0$. For the asymmetric cash flow distribution with $\sigma_{d}=1.3 \sigma_{u}$, the upside Sharpe ratio is 1.3 times the downside Sharpe ratio and the Pearson mode skewness is $s=-0.19$. The empirical Sharpe ratio estimates for the symmetric and asymmetric (downside and upside) models are $\theta^{*}=0.21, \theta_{d}^{*}=0.29$ and $\theta_{u}^{*}=0.372$, respectively. 
These empirical results underscore the importance of higher-order risks and higher-order risk behaviors in the determination of credit spreads and the pricing of corporate bonds.

\subsection{Data and empirics: sample from 2008 to 2014}

To contrast our empirical findings with most recent events, we extend our analysis to the period from 2008 to 2014 where bond transaction data are fully disseminated. ${ }^{3}$ Specifically, we collect firm level data connecting equity and fundamental variables to bond transaction data. Equity and fundamental data are collected from the Bloomberg terminal. Transaction data are collected from TRACE. For a given firm $i$, we compute the leverage ratio as the total debt to total assets. Total debt equals the short term debt plus half the long term debt. The firm's asset level and volatility are backed out from calibrating Merton model to match the firm's market capitalization and the observed outstanding debt. Firm level distance to default is given by

$$
D D_{i}=\frac{\ln \left(\frac{V_{i, 0}}{D_{i}}\right)+\left(\mu_{i, A}-\frac{\sigma_{i, A}^{2}}{2}\right) T}{\sigma_{i, A} \sqrt{T}}
$$

where $V_{i, 0}$ is the total assets of the firm at time $0, \sigma_{i, A}$ is the volatility of assets, $\mu_{i, A}$ is the asset return proxied by the firm's average weighted cost of capital (i.e. the cost of debt plus the cost of equity), $D_{i}$ is the total debt as defined earlier. The time to maturity is denoted by $T$, and $D D_{i}$ is the distance to default. Summary statistics for fundamental variables are presented below. Firms are grouped by rating categories according to Bloomberg assigned default probability and Moody's rating scheme. We use firm-specific fundamentals to compute a firm level sharpe ratio as:

$$
\theta_{i}=\frac{\mu_{i, A}-r_{f}}{\sigma_{i, A}}
$$

where $\mu_{i, A}$ and $\sigma_{i, A}$ are obtained from the Merton model. The risk free rate $r_{f}$ is proxied by the onthe-run treasury yield with corresponding maturity obtained from Bloomberg. Credit spreads are calculated as the difference between the bond yield and the risk free rate proxied by the treasury yield with the same maturity. ${ }^{4}$ We opt for Bloomberg default probability data as their system covers about the full universe of public companies in North America whereas Moody's notation system rates less than $20 \%$ of the companies. We then map the Bloomberg default probabilities to Moody's rating letters using the appropriate default probability bucket for each rating category.

\footnotetext{
${ }^{3}$ Bond data are available in TRACE since 2004, yet about $99 \%$ of the bonds records in the system are fully disseminated starting from 2008.

${ }^{4}$ Daily data on the on-the-run Treasury rates for all available maturities ( 1 month to 30 years) allow us to construct a daily risk-free curve for any specific maturity.
} 
Tables 2 and 3 present the descriptive statistics on fundamental variables for AAA-rated and BBB-rated firms, respectively. Among the variables, the leverage is computed as total debt to total asset ratio. One, four, and ten years cumulative default probabilities are extracted from the Merton model. The distance to default (DD), inverse distance to default (IDD), and asset volatility are also backed out from the Merton model. We include the inverse distance to default among our variables for comparison with previous studies. Expected asset returns are total equity returns and bond returns. Returns on Assets correspond to trailing 12 months net income divided by average total assets. The credit spread is an average of each rating spreads to the risk-free rate (treasury yield) with equivalent maturity. Finally, the Sharpe ratio is calculated using the difference between the asset returns and risk-free rate divided by the asset volatility. 
Table 2: Descriptive statistics for AAA-rated US firms (Jan. 2008 to Feb. 2014)

\begin{tabular}{lcccc} 
& Min & Max & Mean & STD \\
\hline DP cum 1-year (\%) & 0.0000 & 0.0002 & 0.0001 & 0.00004 \\
DP cum 4-year (\%) & 0.0009 & 0.0124 & 0.0051 & 0.0022 \\
DP cum 10-year (\%) & 0.0031 & 0.0627 & 0.0239 & 0.0124 \\
Leverage & 0.2376 & 0.5960 & 0.5235 & 0.0946 \\
Expected Asset Return & 0.0249 & 0.1547 & 0.0681 & 0.0156 \\
Expected Asset Return Volatility & 0.0190 & 0.3580 & 0.1301 & 0.0436 \\
Return on Asset & -0.0264 & 0.0843 & 0.0063 & 0.0079 \\
Credit Spread (bp) & 58.3000 & 213.6000 & 113.0738 & 31.5876 \\
Sharpe ratio & 0.0013 & 1.2201 & 0.4120 & 0.1402 \\
Distance to Default & 4.8042 & 30.0000 & 14.9598 & 4.4108 \\
Inverse Distance to Default & 0.0333 & 0.2082 & 0.0757 & 0.0331 \\
\hline Number of Monthly Observations & 21836 & & & \\
Number of US Firms & 261 & & & \\
Number of US Bonds & 1228 & & & \\
\hline
\end{tabular}

The table reports summary statistics on fundamentals for AAA-rated US firms. DP cum 1-year (resp. DP cum 4-year) refers to the Bloomberg one (resp. four) year issuer's cumulative default probability. The ten year issuer's cumulative default probability (DP cum 10-year) is extrapolated. Leverage is the ratio of total debt to total assets. Expected Asset Return is the Bloomberg estimate of the expected return on debt and equity. Expected Asset Return Volatility is the standard deviation of Expected Asset Returns. Return on Assets is the trailing 12 months net income divided by average total assets. Credit Spread is the spread between the bond yield and the interpolated on-the-run Treasury yield with the same maturity. The Sharpe ratio if the ratio of excess asset returns and asset return volatility. The distance to default (DD) is the Merton-implied ratio of firm value to debt value and the inverse distance to default (IDD) is its inverse. 
Table 3: Descriptive statistics for BBB-rated US firms (Jan. 2008 to Feb. 2014)

\begin{tabular}{lcccc} 
& Min & Max & Mean & STD \\
\hline DP cum 1-year (\%) & 0.0010 & 0.0052 & 0.0022 & 0.0011 \\
DP cum 4-year (\%) & 0.1637 & 0.9806 & 0.3190 & 0.1232 \\
DP cum 10-year (\%) & 0.0274 & 2.5795 & 0.7960 & 0.4221 \\
Leverage & 0.4131 & 0.9413 & 0.7830 & 0.1100 \\
Expected Asset Return & 0.0256 & 0.1761 & 0.0628 & 0.0178 \\
Expected Asset Return Volatility & 0.0249 & 0.9294 & 0.2417 & 0.1244 \\
Return on Asset & -0.0689 & 0.0498 & 0.0020 & 0.0056 \\
Credit Spread (bp) & 187.9000 & 467.2000 & 270.2893 & 53.533 \\
Sharpe ratio & 0.00009 & 1.9572 & 0.1858 & 0.1016 \\
Distance to Default & 1.4032 & 8.9475 & 4.9522 & 1.5976 \\
Inverse Distance to Default & 0.1118 & 0.7127 & 0.2338 & 0.1092 \\
\hline Number of Monthly Observations & 20025 & & & \\
Number of US Firms & 324 & & & \\
Number of US Bonds & 1399 & & & \\
\hline
\end{tabular}

The table reports summary statistics on fundamentals for BBB-rated US firms. DP cum 1-year (resp. DP cum 4-year) refers to the Bloomberg one (resp. four) year issuer's cumulative default probability. The ten year issuer's cumulative default probability (DP cum 10-year) is extrapolated. Leverage is the ratio of total debt to total assets. Expected Asset Return is the Bloomberg estimate of the expected return on debt and equity. Expected Asset Return Volatility is the standard deviation of Expected Asset Returns. Return on Assets is the trailing 12 months net income divided by average total assets. Credit Spread is the spread between the bond yield and the interpolated on-the-run Treasury yield with the same maturity. The Sharpe ratio if the ratio of excess asset returns and asset return volatility. The distance to default (DD) is the Merton-implied ratio of firm value to debt value and the inverse distance to default (IDD) is its inverse. 
We now present the model-implied spreads as per Equations (13) and (17) using the new sample period (Jan. 2008 to Dec. 2014) and compare them with their historical levels. From 2008 to 2014, the 4-year BBB and AAA cumulative default rates estimated for the period are $0.319 \%$ and $0.01 \%$, respectively. The 10-year $\mathrm{BBB}$ and $\mathrm{AAA}$ cumulative default rates estimated for the period are $0.796 \%$ and $0.02 \%$, respectively.

In our new sample, the average Sharpe ratio of a typical firm is approximately $\theta=0.186$. The downside (resp. upside) volatility weighted average Sharpe ratio is $\theta_{d}=0.590$ (resp. $\theta_{u}=0.220$ ). It is important to recall that Sharpe ratios for the new sample period (2008-2014) are computed from expected asset (but not equity) returns. The sample distribution of these asset returns is positivelyskewed with a Pearson mode skewness $s$ of 0.90 and departs from normality according standard tests (Kolmogorov-Smirnov, Cramer-von Mises, and Anderson-Darling). Details are available from the authors. Thus, our new data set differs from that used in Chen et al. (2009) in many ways. Our underlying distribution is based on asset return dynamics, whereas Chen et al. (2009) use equity returns. Moreover, Their average BBB-AAA spread is equal to 109 bp (1974-1998) while we have 157 bp (2008-2014). The major difference between Chen et al.'s (2009) empirical investigation and ours is however about default probabilities. Our period of analysis is characterized by lower probabilities of default. For instance, the 4-year cumulative default probability for BBB-rated bonds during the period 1970-2001 is $1.55 \%$, that is five times higher than the default rate in 2008$2014(0.32 \%)$. According to Standard and Poors, the annual average default probability during our period of analysis is $0.16 \%$ for all maturities and sectors. Firms in the financial sector are not included in our study. This obviously implies lower average default model-based BBB-AAA spreads for the new sample.

Table 4 shows the model-implied spreads for a grid of (downside/upside volatility weighted) Sharpe ratios including historical average values. Interestingly, the increase in the model implied BBB-AAA spread delivered by the asymmetric specification with respect to the symmetric benchmark model is quite impressive both at 4-year (57.8 bps versus 11.4 bps) and 10-year (92.8 bps versus 17 bps) maturities. 
Table 4: Model-implied BBB-AAA spreads for different Sharpe ratios (Jan. 2008 to Dec. 2014)

\begin{tabular}{|c|c|c|c|c|c|c|}
\hline \multirow[b]{2}{*}{ Sharpe ratio } & \multicolumn{3}{|c|}{ 4-year maturity } & \multicolumn{3}{|c|}{ 10-year maturity } \\
\hline & $\mathrm{BBB}$ & AAA & BBB-AAA & $\mathrm{BBB}$ & AAA & BBB-AAA \\
\hline \multicolumn{7}{|c|}{ Panel A: Symmetric model $\sigma_{d}=\sigma_{u}=\sigma ; s=0$} \\
\hline$\theta_{d}=\theta_{u}=\theta$ & \multicolumn{6}{|c|}{ Spreads in basis points } \\
\hline 0.15 & 9.8 & 0.5 & 9.4 & 13.7 & 0.6 & 13.2 \\
\hline $0.186=\theta^{*}$ & 12.0 & 0.6 & 11.4 & 17.8 & 0.9 & 17.0 \\
\hline 0.20 & 12.9 & 0.6 & 12.3 & 19.6 & 1.0 & 18.7 \\
\hline 0.25 & 16.8 & 0.9 & 15.9 & 27.5 & 1.6 & 25.9 \\
\hline 0.30 & 21.6 & 1.2 & 20.4 & 37.7 & 2.5 & 35.2 \\
\hline 0.40 & 34.9 & 2.3 & 32.7 & 67.0 & 6.0 & 61.0 \\
\hline
\end{tabular}

Panel B: Asymmetric model $\sigma_{d}=0.4 \sigma_{u} ; s=0.90$

\begin{tabular}{lccccccc}
$\theta_{d}$ & $\theta_{u}=0.4 \theta_{d}$ & & & & & & \\
0.15 & 0.060 & 9.3 & 0.4 & 8.9 & 12.4 & 0.6 & 11.9 \\
0.20 & 0.080 & 12.0 & 0.6 & 11.4 & 17.2 & 0.9 & 16.4 \\
0.25 & 0.100 & 15.2 & 0.8 & 14.5 & 23.3 & 1.4 & 22.0 \\
0.30 & 0.120 & 19.3 & 1.1 & 18.2 & 31.0 & 2.2 & 28.9 \\
0.40 & 0.160 & 30.1 & 2.1 & 28.1 & 51.7 & 4.9 & 46.8 \\
$0.59=\theta_{d}^{*}$ & $0.220=\theta_{u}^{*}$ & 63.8 & 6.1 & 57.8 & 111.3 & 18.5 & 92.8 \\
\hline
\end{tabular}

The 4-year BBB (AAA) default rate is $0.319 \%(0.01 \%)$. The 10-year BBB (AAA) default rate is $0.796 \%(0.02 \%)$. The expected loss rate is $51.4 \%$. For the symmetric cash flow distribution with $\sigma_{d}=\sigma_{u}=\sigma$, the downside and upside Sharpe ratios are equal $\theta_{d}=\theta_{u}=\theta$ and the Pearson mode skewness is $s=0$. For the asymmetric cash flow distribution with $\sigma_{d}=0.4 \sigma_{u}$, the upside Sharpe ratio is nearly 0.4 times the downside Sharpe ratio and the Pearson mode skewness is $s=0.90$. The empirical Sharpe ratio estimates for the symmetric and asymmetric (downside and upside) models are $\theta^{*}=0.186, \theta_{d}^{*}=0.590$ and $\theta_{u}^{*}=0.220$, respectively. 
Figure 2: Credit Spread Dynamics (Jan. 2008 to Dec. 2014)
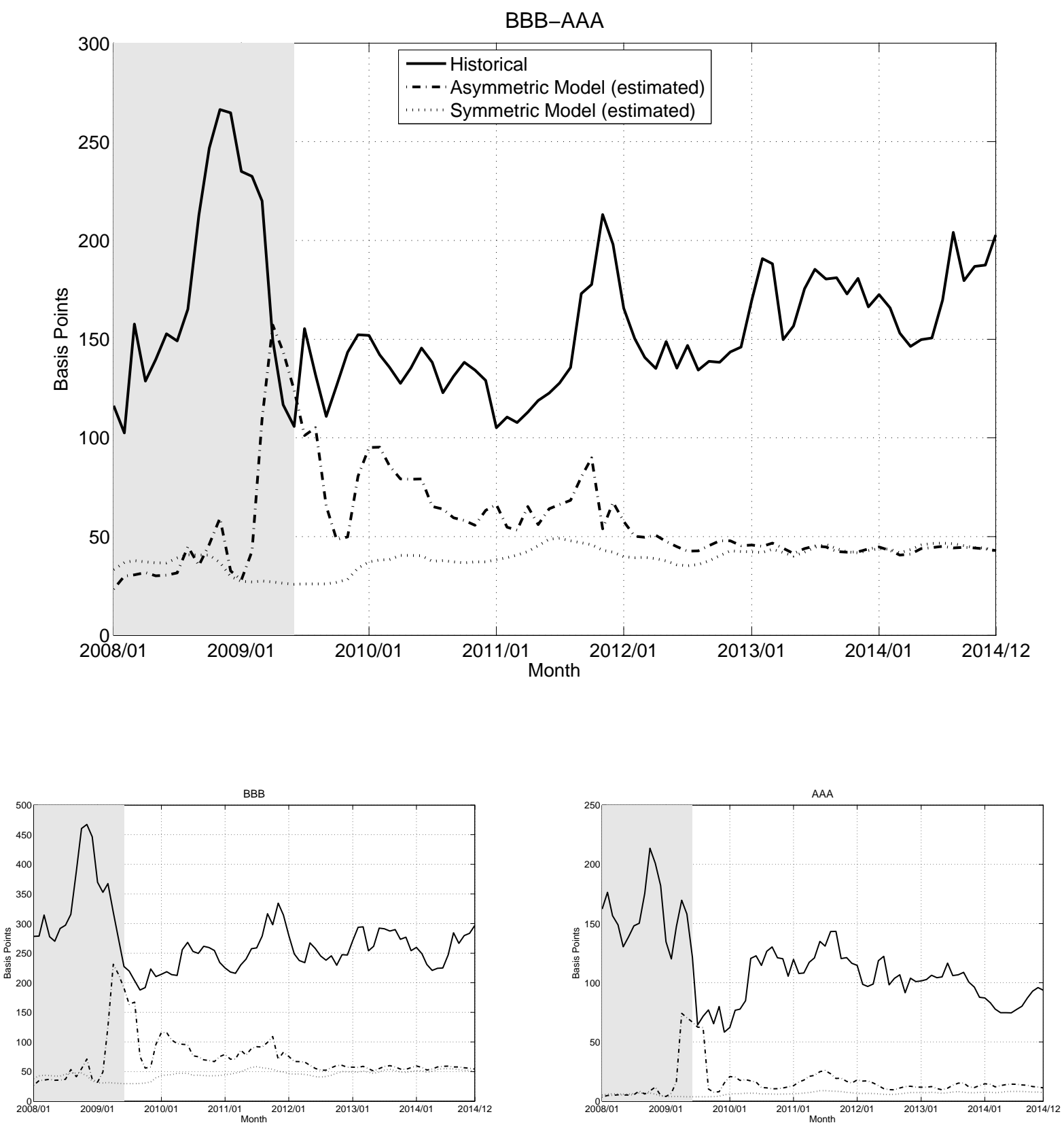

We plot monthly time series of BBB-AAA (top panel), BBB (bottom-left panel), and AAA (bottom-right panel) credit spreads in basis points from Jan. 2008 to Dec. 2014. Each panel shows historical series (solid line) along with asymmetric (dash-dotted line) and asymmetric (dotted line) model-implied credit spreads dynamics. Model-implied spreads are based on 4-year default rates. The shaded area represents NBER recession. 
We now turn our focus to the dynamics of the spreads implied by each specification. To this end, we compute monthly model-implied credit spreads based on monthly time-varying Sharpe ratios. Figure 2 provides a stark demonstration of the dynamic performance of the asymmetric model, especially during the 2008 financial meltdown. Indeed from January 2008 to December 2009, the asymmetric model gives an average BBB-AAA spread of 62 bp (versus 32 bp for the benchmark symmetric model), or nearly $37 \%$ (versus $19 \%$ for the benchmark symmetric model) of the average historical spread level (166 bp). Over the entire (2008-2014) observation window, the historical average BBB-AAA spread is about $157 \mathrm{bp}$. Clearly, the asymmetric model explains a larger fraction of the historical spread as it delivers an average spread of $58 \mathrm{bp}$, whereas the average symmetric model-implied spread is $39 \mathrm{bp}$. Note that in figure 2, model-impled spread are computed with 4-year default rates while historical spreads are constructed from traded corporate bonds with an average maturity of 7 years. We now investigate to what extent the unexplained historical spread levels can be related to illiquidity risk factors affecting corporate bonds.

\section{$5 \quad$ Illiquidity component dynamics}

Up to now, our analysis has been devoted to understanding the default component of the total credit spread, in the spirit of Elton et al. (2001), Longstaff et al. (2005) and Chen et al. (2015). In this section, we shift our attention to the residual of total credit spread that is not explained by default risk. At this point, we consider the two (default and liquidity) risks as independent, and therefore, we do not model any explicit default-liquidity dependence between them.

\subsection{Illiquidity indexes}

We construct bond level illiquidity indexes using bond characteristics and bond trading information. When bond trading information are missing traders account for the bond age and the amount issued (size of the trade) to identify the most liquid bonds. For instance, a bond is more liquid when it is recently issued (young bonds with an age less than 12 months) then it tends to be less liquid toward illiquid as it becomes older. The dollar amount issued also increases with bond liquidity. For instance, some portfolio managers use an amount issued of US $\$ 5$ millions as a cut-off between most liquid and least liquid bonds.

Illiquidity measures based on trading prices are now widely used (see for instance Dick-Nielsen, Feldhütter, and Lando, 2012, and references therein). Specifically, we measure the price impact of 
trades using the Amihud measure and the average holding period. The Amihud measure accounts for the bond absolute return computed at the trade level relative to a dollar volume of trade. The Amihud is wider for illiquid bonds. The average holding period (hereafter, holding period) is defined as the volume traded divided by the amount outstanding. The larger the average holding period, the lower the bond turnover and the less illiquid the bond. We measure the bond implied bid/ask spread using the imputed roundtrip cost (IRC) and Roll measure (Roll). The IRC is measured when a roundtrip transaction is identified between three or more market participants suggesting that at least two dealers are involved in the same trade with a client. A roundtrip transaction identifies the highest price charged to the client and the lowest price charged to the dealer for the same transaction. The relative spread between the highest and lowest trading prices is likely to capture the size of the bid/ask spread of the trade. Roll measures an implied bid/ask spread by identifying trades with a negative covariance between successive returns. Higher IRC and Roll measures imply lower liquidity. We measure the liquidity risk using the standard deviation of the Amihud measure (Amihud risk) and IRC measures (IRC risk). Larger values of these two measures indicate a higher uncertainty about the bond liquidity, thus higher illiquidity. We measure the zero trades using the number of days within the month the firm's single bond did not trade (zero bond) and we measure the number of days the firm's all bonds did not trade (zero firm).

The eight illiquidity measures which are based on trading prices are computed daily using a rolling window of 21 business days (one month). The age and the size are standardized using the mean and the standard deviation of these measures for the full sample of bonds. For each measure, we define the benchmark for liquid bonds with respect to one particular measure, as its 5th percentile value. The spread between the measure and its 5 th percentile reflects an illiquidity premium. Note that our bond level illiquidity variables are highly correlated. Thus, we run a principal component analysis (PCA) to identify the loading of each original variable in our final illiquidity index. Our first principal component, which explains more than $50 \%$ of the total variability of all our illiquidity variables, has a nearly uniform loading system. Based on these results, we construct an illiquidity index that is an equally weighted factor using the original bond level illiquidity measures. Thus, for each bond we obtain an illiquidity index throughout the study period. These bond level indexes allows us to build idiosyncratic illiquidity series for each rating class (AAA and BBB). For the systematic liquidity index, we construct a single index using bond level illiquidity indexes for all the bonds in the sample. 


\subsection{Explaining model-implied residual spreads by illiquidity indexes}

We now consider the model-implied residual spread $\left(S P^{\text {residual }}\right)$, defined as the difference between the observed historical credit spread $\left(S P^{\text {observed }}\right)$ and default model-based spread $\left(S P^{\text {default }}\right)$ for each rating. To explain model-implied residual spread dynamics, we fit its values to constructed illiquidity indexes in a contemporaneous regression.

For a given rating class $j \in\{A A A, B B B\}$, we consider the following specification

$$
S P_{j}^{\text {residual }}=\alpha_{j}+\beta_{j} l^{S}+\gamma_{j} l_{j}^{I}+e_{j}
$$

where $l^{S}$ is a systematic illiquidity index, $l_{j}^{I}$ denotes an idiosyncratic illiquidity index, and $e_{j}$ is an error term.

The resulting specification for the BBB-AAA residual spread is

$$
S P_{B B B-A A A}^{\text {residual }}=\widetilde{\alpha}+\widetilde{\beta} l^{S}+\widetilde{\gamma}_{B B B} l_{B B B}^{I}+\widetilde{\gamma}_{A A A} l_{A A A}^{I}+\epsilon_{j}
$$

Note that $\widetilde{\beta}=\beta_{B B B}-\beta_{A A A}$ by construction, as we assume that bonds are exposed to the same systematic illiquidity risk factor.

\begin{tabular}{|c|c|c|c|c|c|c|c|c|c|c|c|c|}
\hline \multirow[b]{3}{*}{ Parameters } & \multicolumn{6}{|c|}{ Symmetric model } & \multicolumn{6}{|c|}{ Asymmetric model } \\
\hline & \multicolumn{2}{|c|}{$\mathrm{BBB}$} & \multicolumn{2}{|c|}{ AAA } & \multicolumn{2}{|c|}{ BBB-AAA } & \multicolumn{2}{|c|}{$\mathrm{BBB}$} & \multicolumn{2}{|c|}{ AAA } & \multicolumn{2}{|c|}{ BBB-AAA } \\
\hline & Est & T-stat & Est & T-stat & Est & T-stat & Est & T-stat & Est & T-stat & Est & T-stat \\
\hline \multicolumn{13}{|c|}{ Panel A: Eq. (21) } \\
\hline$\alpha_{j}$ & 157.26 & 12.53 & 81.99 & 6.59 & & & 134.67 & 5.76 & 80.26 & 5.49 & & \\
\hline$\beta_{j}$ & 41.94 & 14.34 & 21.38 & 10.05 & & & 44.01 & 8.07 & 22.88 & 9.15 & & \\
\hline$\gamma_{j}$ & -12.74 & -0.92 & -3.31 & -0.20 & & & -18.39 & -0.72 & -14.37 & -0.73 & & \\
\hline \multicolumn{13}{|c|}{ Panel B: Eq. (22) } \\
\hline$\widetilde{\alpha}$ & & & & & 55.35 & 2.80 & & & & & 84.19 & 3.55 \\
\hline$\widetilde{\beta}$ & & & & & 17.55 & 5.78 & & & & & 21.34 & 5.86 \\
\hline$\widetilde{\gamma}_{B B B}$ & & & & & 35.08 & 2.59 & & & & & 38.35 & 2.36 \\
\hline$\widetilde{\gamma}_{A A A}$ & & & & & -27.42 & -1.25 & & & & & -91.70 & -3.47 \\
\hline$R^{2}(\%)$ & 74.29 & & 57.86 & & 42.98 & & 46.86 & & 52.12 & & 41.24 & \\
\hline
\end{tabular}

Table 5: Regressions of residual spreads on illiquidity indexes (Jan. 2008 to Dec. 2014)

This table shows the results for the regression of residual spread on illiquidity measures by rating class. For each rating class $j(\mathrm{BBB}$ or $\mathrm{AAA})$, we run the regression $S P_{j}^{\text {residual }}=\alpha_{j}+\beta_{j} l^{S}+\gamma_{j} l_{j}^{I}+e_{j}$. To explain the residual BBB-AAA spread, we estimate the relation $S P_{B B B-A A A}^{\text {residual }}=\widetilde{\alpha}+\widetilde{\beta} l^{S}+\widetilde{\gamma}_{B B B} l_{B B B}^{I}+\widetilde{\gamma}_{A A A} l_{A A A}^{I}+\epsilon_{j}$. We report the estimated parameters (Est) with their corresponding t-statistics (T-stat). 
We obtain a set of very interesting results in Table 5. In Panel A, we estimate the residual spread for each rating class and find that the coefficient associated with the idiosyncratic index of illiquidity is not significant when we control for the systematic index of illiquidity. This result is important because, to our knowledge, we are the first to include a systematic risk index in the analysis of the residual (total minus default) spread. This evidence differs from the one documented by DickNielsen, Feldhutter and Lando (2012) who find a significant effect with a similar idiosyncratic index for virtually all rating categories, while not controlling for the systematic index. Moreover, we observe that the systematic illiquidity effect is positive for both rating classes and is higher for $\mathrm{BBB}$ rating than for AAA rating. This finding corroborates the results of previous studies discussed in the literature review using only the idiosyncratic illiquidity risk to explain the residual spread. Overall, the systematic illiquidity risk effect seems more important for corporate bonds than for Treasury bonds, while the idiosyncratic illiquidity risk component tends to have a weak impact on the total credit spread.

The results in Panel B are also important. If we concentrate the discussion on the asymmetric model, we first notice that the BBB-AAA residual spread is positively affected by the common systematic index of illiquidity. This result confirms those in the previous regressions, where we observed a larger effect for the BBB rating than for the AAA rating. In addition, the coefficients of both (AAA and BBB) idiosyncratic indexes of illiquidity are significant meaning that the residual BBB-AAA spread is function of the characteristics of the different rating classes. Specifically, less liquid bonds in each rating class have different effects: the positive effect of BBB less liquid bonds is dominated by the negative effect of AAA less liquid bonds.

Next, we use the model-implied residual spread explained by illiquidity indexes to obtain a time series of the estimated liquidity component for AAA and BBB rating classes. Figure 3 shows a sharp increase in the explained residual spread in the middle of the crisis period for BBB-AAA, BBB-Treasury, and AAA-Treasury spreads. The apparent spikes occur during during the 2008-2009 financial turmoil characterized by a sector wide shortage of liquidity. 
Figure 3: Explained Residual Spread (Jan. 2008 to Dec. 2014)
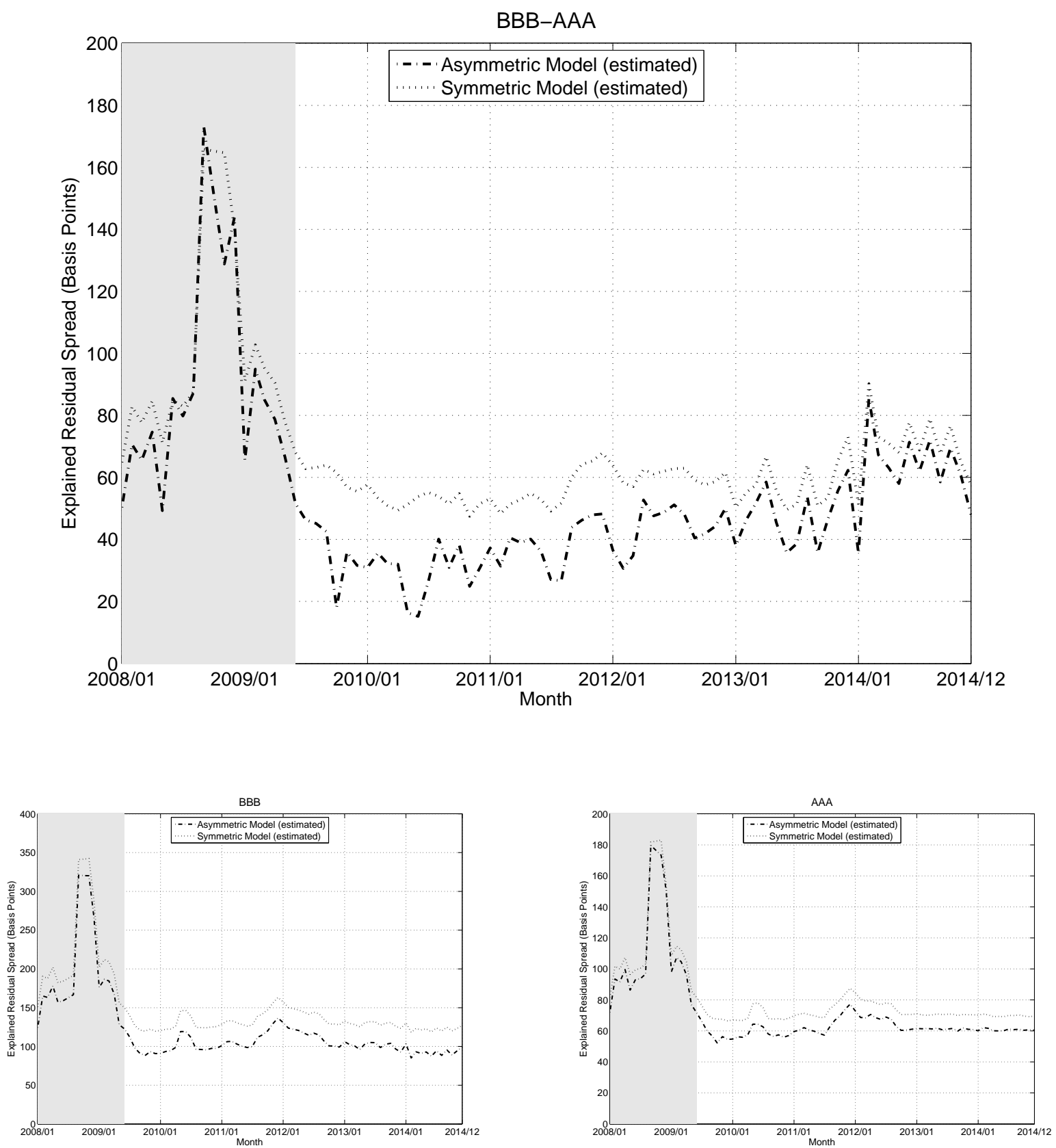

We present the time series of BBB-AAA (top panel), BBB (bottom-left panel), and AAA (bottom-right panel) explained residual spreads based on systematic and idiosyncratic illiquidity indexes for the asymmetric (dash-dotted line) and symmetric (dotted line) specifications from Jan. 2008 to Dec. 2014. Model-implied residual spreads are extracted based on 4-year default rates. The shaded area represents NBER recession. 


\subsection{Recovering the total spread}

By summing default model-based spreads and residual spreads explained by illiquidity index we obtain a proxy for the total spread that is much closer to observed historical credit spread levels. Figure 4 plots model-implied total spread dynamics along with the corresponding historical time series. We observe two distinct spikes inside the shaded NBER recession period. The first spike is likely related to a surge in liquidity disruption risk while the second is driven by corporate default risk. We find that our two-step approach, which extracts the default component of the observed spread based on an asymmetric Merton-type specification, and then explains the residual spread with illiquidity indexes using a regression, matches nearly $70 \%$ (resp. $72.25 \%$, and $77.89 \%$ ) of the BBB-AAA (resp. BBB, and AAA) average historical spread from 2008 to 2014. 
Figure 4: Explained Total Spread (Jan. 2008 to Dec. 2014)
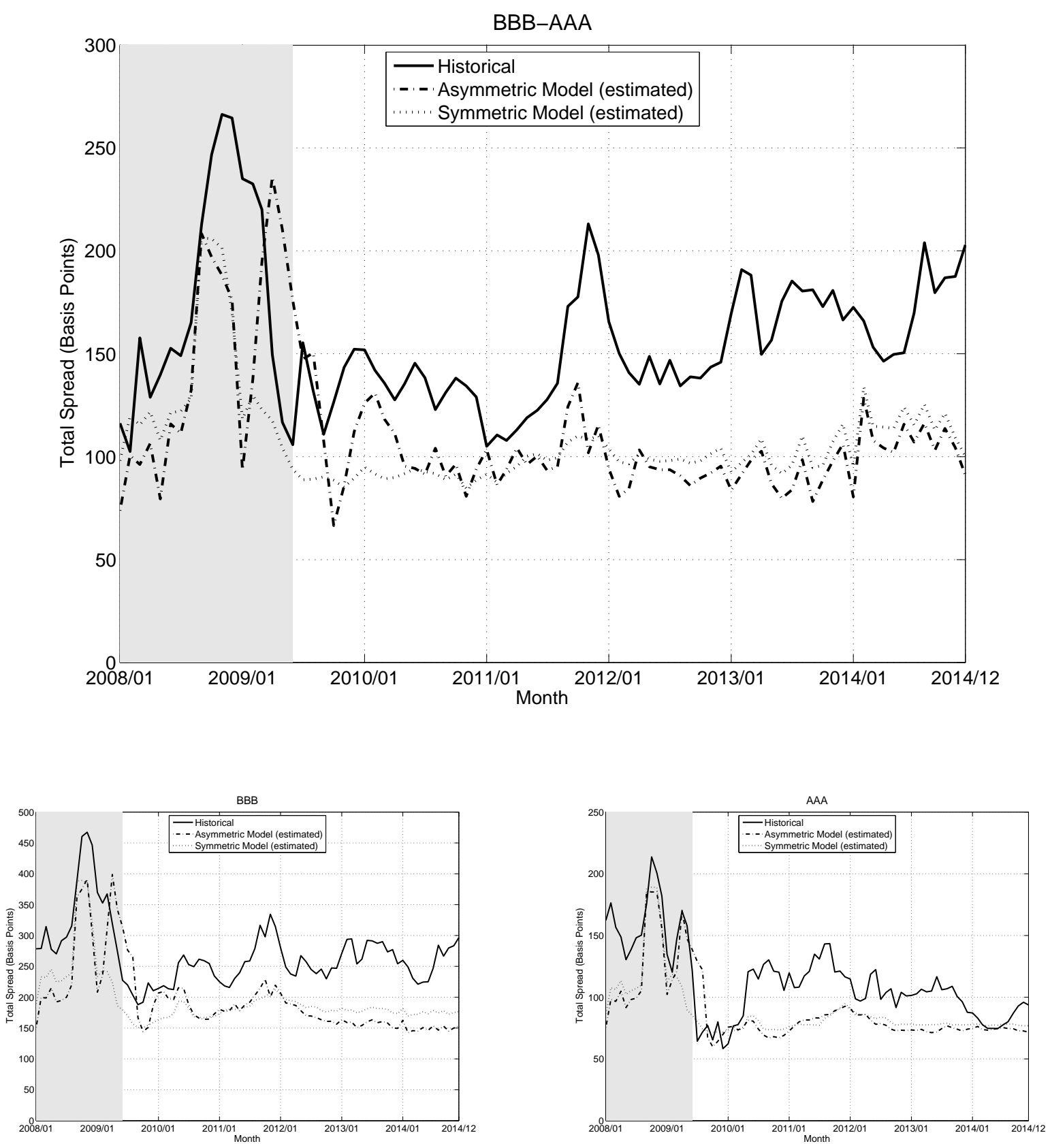

We present the time series of BBB-AAA (top panel), BBB (bottom-left panel), and AAA (bottom-right panel) explained total spreads based on systematic and idiosyncratic illiquidity indexes for the asymmetric (dash-dotted line) and symmetric (dotted line) specifications from Jan. 2008 to Dec. 2014. Historical credit spread levels (solid line) are also shown for comparison. Model-implied residual spreads are extracted based on 4-year default rates. The shaded area represents NBER recession. 


\section{Conclusion and discussion}

In this paper, we propose a new approach to study the credit risk puzzle with new data obtained from Bloomberg and covering the post-financial crisis period characterized by low default rates and high illiquidity in credit markets. Our model can be viewed as an extension of the Longstaff et al. (2005) and Chen et al. (2008) models. We characterize the importance of higher-order risks in explaining the observed credit spreads by introducing a split normal asset return distribution in the Chen at al. (2008) default model, and analyze whether this assumption can deliver realistic credit spreads. We show that the split normal distribution is more appropriate to explain the default component of the BBB-AAA spread than the usual gaussian distribution.

We first consider the same study period (1974-1998) as Chen et al (2008), where the average default rate for BBB bonds is $1.55 \%$. By specifying a flexible asymmetric cash flow return distribution, we increase the 4-year model-implied spread obtained by Chen et al (2008) by $43.53 \%=(78.8$ bp/54.9 bp-1). For a maturity of 10 years, we observe an increase of $47.98 \%=(109.2$ bp/73.8 bp- 1$)$ in the calibrated spread when moving from the symmetric to the asymmetric modelization. In fact, the asymmetric split normal model yields a BBB-AAA spread that is much closer to the historical level. Specifically, the asymmetric split normal model explains $78.00 \%=(109.2 \mathrm{bp} / 140 \mathrm{bp})$ of the 10-year historical BBB-AAA spread whereas the symmetric gaussian model matches only $52.71 \%=(73.8 \mathrm{bp} / 140 \mathrm{bp})$ of the 10-year observed spread.

During our second period of analysis (2008-2014), the average BBB 4-year default probability collapses to $0.32 \%$, which is very low. Over the entire observation window, the historical average BBB-AAA spread retrieved from TRACE database is about 157 basis points, much higher than in the previous period for the same maturity (109 bp). Again, the asymmetric model explains a larger fraction of the historical spread as it delivers an average default spread of 58 basis point, whereas the average default spread for symmetric model-implied spread is 39 basis points. The results suggest, however, that the historical spread between the two ratings must contain at least another component than default risk.

To refine our study, we then link the residual (non-default-model-implied) spread to two liquidity risk factors. The first one is extracted from several measures of idiosyncratic illiquidity variables available in the literature (Longstaff, Mithal, and Neis, 2005; Dick-Nielsen, Feldhütter, and Lando, 2012; Friewald, Jankowitsch, and Subrahmanyam, 2012; and Bao, Pan, and Wang, 2011). We add to this first factor a systematic risk factor defined as weighted sum of ten illiquidity premiums. 
Continuing the analysis with our asymmetric model to explain the default component, we first show that the BBB-AAA residual spread is positively affected by the common systematic index of illiquidity. Moreover, the coefficients of the two idiosyncratic index of illiquidity are significant meaning that the BBB-AAA residual spread is function of the illiquidity characteristics of the two different ratings and, surprisingly, the positive effect of $\mathrm{BBB}$ bonds is dominated by the negative effect of AAA bonds.

Our two-step approach, which extracts the default component of the observed spread based on an asymmetric Chen et al (2008) type specification, and then explains the residual spread with two illiquidity indexes using a regression, matches nearly $70 \%$ (resp. $72.25 \%$, and $77.89 \%$ ) of the BBB-AAA (resp. BBB, and AAA) average historical spread from the beginning of January 2008 to the end of December 2014.

It may be worth noting that a fatter-tailed distribution like a split Student- $t$ distribution lies among the flexible distributions to consider in order to capture asymmetries. See for instance Fernandez and Steel (1998), and Rubio and Steel (2014), among others. ${ }^{5}$ We should also emphasize that although bonds are now much more actively traded, bond markets remain relatively illiquid as compared to stock markets. For instance in the U.S., only about 1,000 companies out of a total of 40,000 public companies (according to Bloomberg) have corporate bonds that are traded in TRACE (about 50,000 total bonds) across different sectors. The sample is even smaller for straight bullet bonds (around 10,000 bonds). These statistics suggest that one may still need to bucket the bonds, say by rating category to increase the sample size of the bucket. This common practice implicitly assumes that bonds in a given rating bucket are homogeneous, although they are issued by different firms, have different ages and durations. To which extent this conventional practice affects the empirical results in the literature is still an open question. Ultimately, a possible refinement of this study would be to consider firms with sufficient bonds and data and implement our methodology using bond level or firm level credit spreads as opposed to rating bucket level credit spreads. We expect that within this context, the asymmetric model will perform even better as it will capture more asymmetric patterns in risks and risk attitudes. Another standard assumption that we adopt is a fixed loss given default rate given the limited number of defaults. Yet, some studies provide evidence suggesting that the loss given default rate varies with firms in the same rating bucket (Altman et al. 2005) and with the business cycle (Dionne et al. 2010). Thus, considering time varying loss given default rates along with our time varying default rates

\footnotetext{
${ }^{5}$ Though richer distributions are desirable, deriving closed-form credit spread expressions might be challenging.
} 
could increase the default premium relative to total credit spreads. Finally, as we show that the systematic illiquidity component of credit spreads explains a sizeable fraction of the total premium, it would be interesting to further analyze the dynamics between default and illiquidity regimes in the spirits of (Maalaoui et al. 2014), and then model their dependence using a framework similar to that of Chen et al (2009). 


\section{References}

Acharya V., and Pedersen L. (2005), Asset Pricing with Liquidity Risk, Journal of Financial Economics 77,375-410.

Altman E., Brady B., Resti A., and Sironi A. (2005), The Link Between Default And Recovery Rates: Theory, Empirical Evidence and Implications, Journal of Business $78,2203-2228$.

Amihud Y., and Mendelson H. (1986), Asset Pricing and the Bid-Ask Spread, Journal of Financial Economics 17, 223-249.

Ang A., Bekaert G. (2002), International asset allocation with regime shifts, Review of Financial Studies 15, 1137-1187.

Ang A., Chen J. (2002), Asymmetric correlations of equity portfolios, Journal of Financial Economics 63, 443-494.

Ang A., Chen J., and Xing Y. (2006), Downside risk, Review of Financial Studies 19, 1191-1239.

Balakrishnan N., and Lai C. D. (2009), Continuous Bivariate Distributions, 2nd ed. Springer, New York.

Bao J., Pan J., and Wang J. (2011), The Illiquidity of Corporate Bonds, Journal of Finance 66, 911-946.

Bongaerts D., de Jong F., and Driessen J. (2011), Derivative Pricing with Liquidity Risk: Theory and Evidence from the Credit Default Swap Market, Journal of Finance 66, 203-240.

Buraschi A., Trojani F., and Vedolin A. (2014), Economic Uncertainty, Disagreement, and Credit Markets, Management Science 60, 1281-1296.

Britton E., Fisher P., and Whitley J. (1998), The inflation report projections: understanding the fan chart, Bank of England Quarterly Bulletin, February 1998.

Chen H. (2010), Macroeconomic conditions and the puzzles of credit spreads and capital structure, Journal of Finance 65, 2171-2212.

Chen H., Cui R., He Z., and Milbradt K. (2015), Quantifying Liquidity and Default Risks of Corporate Bonds over the Business Cycle, Working Paper, 58 pages.

Chen L., Collin-Dufresne P., Goldstein R. S. (2009), On the Relation Between the Credit Spread Puzzle and the Equity Premium Puzzle, Review of Financial Studies 
$22,3367-3407$.

Collin-Dufresne P., Goldstein R. S., Martin J. S. (2001), The Determinants of Credit Spread Changes, Journal of Finance 56, 2177-2208.

Cuadras C. M. (2002), On the covariance between functions, Journal of Multivariate Analysis 81, 19-27.

Dick-Nielsen, Feldhütter, and Lando, (2012) Corporate Bond Liquidity Before and After the Onset of the Subprime Crisis, Journal of Financial Economics 103, 471-472.

Dionne G., Li J., Okou C. (2013), An Extension of the Consumption-based CAPM Model, Working paper, available at http://papers.ssrn.com/sol3/papers.cfm?abstract_id=2155180.

Dionne G., Gauthier G., Hammami K., Maurice M., Simonato J. G. (2010), Default Risk in Corporate Yield Spreads, Financial Management, Summer, 707-731.

Dionne G., Gauthier G., Hammami K., Maurice M., Simonato J. G. (2011), A reduced form model of default spreads with Markov-switching macroeconomic factors, Journal of Banking and Finance 35, 1984-2000.

Dionne G., Maalaoui Chun O. (2013), Default and Liquidity Regimes in the Bond Market, Canadian Journal of Economics, 46, 1160-1195.

Edwards A. M., Harris L. E., and Piwowar M. S. (2007), Corporate Bond Market Transaction Costs and Transparency, Journal of Finance 62, 1421-1451.

Eeckhoudt, L, Schlesinger, H. (2006), Putting risk in its proper place, The American Economic Review 96, 280-289.

Elton E. J., Gruber M. J., Agrawal D., Mann C. (2001), Explaining the Rate Spread on Corporate Bonds, Journal of Finance 56, 247-277.

Embrechts P. (2009), Copulas: A personal view, Journal of Risk and Insurance 76, $639-650$.

Ericsson J., Renault O. (2006), Liquidity and Credit Risk, Journal of Finance 61, 22192250.

Fernàndez C., Steel M. F. J. (1998), On Bayesian modeling of fat tails and skewness, Journal of the American Statistical Association 93, 359-371.

Feunou B., Jahan-Parvar M. R., and Tédongap R. (2013), Modeling Market Downside Volatility, Review of Finance 17, 443-481.

Friewald N., Jankowitsch R., and Subrahmanyam M. (2012), Illiquidity or Credit Dete- 
rioration: A Study of Liquidity in the U.S. Corporate Bond Market during Financial Crises, Journal of Financial Economics 105, 18-36.

Fujiwara I., Korber L., and Nagakura D. (2011), How Much Asymmetry is There in Bond Returns and Exchange Rates?, Globalization and Monetary Policy Institute Working Paper 93.

Galton F. (1886), Regression towards mediocrity in hereditary stature, Journal of the Anthropological Institute of Great Britain and Ireland 15, 246-263.

Gibbons, J. F. and Mylroie, S. (1973), Estimation of impurity profiles in ion-implanted amorphous targets using joined half-Gaussian distributions, Applied Physics Letters $22,568-569$.

Giesecke K., Longstaff F. A., Schaefer S., Strebulaev I. (2011), Corporate Bond Default Risk: A 150-Year Perspective, Journal of Financial Economics 102, 233-250.

Hogan W. W., Warren J. M. (1974), Toward the Development of an Equilibrium Capital Market Model Based on Semivariance, Journal of Financial and Quantitative Analysis 9, 1-12.

Huang J. Z., Huang M. (2012), How Much of the Corporate-Treasury Yield Spread is Due to Credit Risk?, Review of Asset Pricing Studies, 2, 153-202.

Hull J., White A. (2013), LIBOR vs. OIS: The Derivatives Discounting Dilemma, Journal Of Investment Management, 11, 14-17.

John S. (1982), The three-parameter two-piece normal family of distributions, Communications in Stattistics - Theory and methods 11, 879-885.

Johnson N.L., Kotz S., and Balakrishnan N. (1994), Continuous Univariate Distributions, Volume 1, John Wiley \& Sons, p. 173.

Jondeau E., Rockinger M. (2006), Optimal portfolio allocation under higher moments, European Financial Management, 12, 29-55.

Kimball M. S. (1990), Precautionary saving in the small and in the large, Econometrica $58,53-73$.

Lehmann E. L. (1966), Some concepts of dependence, Annals of Mathematical Statistics $37,1137-1153$.

Li J. (2011), The demand for a risky asset in the presence of a background risk, Journal of Economic Theory, 146, 372-391.

Lin H., Wang J., Wu C. (2011), Liquidity Risk and Expected Corporate Bond Returns, 
Journal of Financial Economics, 99, 628-650.

Maalaoui Chun O., Dionne G., and François P. (2014), Credit Spread Changes within Switching Regimes, Journal of Banking and Finance, 49, 41-55.

Maalaoui Chun O., Dionne G., and François P. (2014), Detecting Regime Shifts in Credit Spreads, Journal of Financial and Quantitative Analysis, 49, 1339-1364.

Merton R. (1974), On the Pricing of Corporate Debt: the Risk Structure of Interest Rates, Journal of Finance 29, 449-470.

Modica S., Scarsini M. (2005), A note on comparative downside risk aversion, Journal of Economic Theory 122, 267-271.

Ospina R., Ferrari S. L. P. (2010), Inflated beta distributions, Statistical Papers 51, $111-126$.

Rubio F., Steel M. F. J. (2014), Inference in Two-Piece Location-Scale Models with Jeffreys Priors, Bayesian Analysis 9, 1-22.

Schwarz, K. (2015), Mind the Gap: Disentangling Credit and Liquidity in Risk Spreads, Working Paper, University of Pennsylvania.

Stein C. (1973), Estimation of the Mean of a Multivariate Normal Distribution, Proceedings of the Prague Symposium on Asymptotic Statistics, 345-381.

Tesfatsion L. (1976), Stochastic dominance and the maximization of expected utility, Review of Economic Studies 43, 301-315.

Warga A. (1998), Fixed Income Database, University of Houston, Houston, Texas.

Wright R. (1987), Expectation dependence of random variables, with an application in portfolio theory, Theory and Decision 22, 111-124. 


\section{Appendix}

\section{A Higher-order risks in a standard consumption-based equilibrium credit model}

To further support our argument that asymmetry matters, we derive a general equilibrium credit model that is flexible enough to accommodate higher-order risks and rationalize higher-order risk attitudes - such as downside risk that pertains to a prudent behavior - in the pricing of risky bonds. We highlight the importance of properly measuring the asymmetric dependence between the payoff of a risky and our state variable, which is consumption. To this end, we employ the concept of expectation dependence to extend the pricing assumption of risk aversion (second-order risk) to prudence (third-order risk) ${ }^{6}$ Eeckhoudt and Schlesinger (2006) provide an intuitive review of higher-order risks using lottery pairs. We now introduce the concept of expectation dependence.

\section{A1 Overview of the concept of expectation dependence}

The concept of correlation is a commonly-used measure of dependence since the early work of Galton (1886). However, in some economic and financial analysis with non-normal distributions, stronger measures of dependence are required to obtain robust stylized facts. A survey of the literature on assessing statistical dependence is provided by Embrechts (2009).

Let's consider the concept of quadrant dependence proposed by Lehmann (1966).

Assume $\tilde{x} \times \tilde{y} \in R \times R$ are two continuous random variables. Let $F_{x}(x)$ and $F_{y}(y)$ denote the marginal distributions of $\tilde{x}$ and $\tilde{y}$. The joint distribution of these two covariates is denoted by $F(x, y)$.

Definition A.1 (Lehmann, 1966) The random pair $(\tilde{x}, \tilde{y})$ is positive quadrant dependent, denoted $P Q D(\tilde{x}, \tilde{y})$, if

$$
F(x, y) \geq F_{x}(x) F_{y}(y) \quad \text { for all }(x, y) \in R \times R .
$$

One can rewrite this inequality as

$$
F_{x}(x \mid \tilde{y} \leq y) \geq F_{x}(x)
$$

To help better understand the concept of positive quadrant dependence, Lehmann (1966, p. 1143) provides the following intuition of Definition A.1: "Knowledge of $\tilde{y}$ being small increases the probability of $\tilde{x}$ being small." Positive quadrant dependence (PQD) is useful to model dependent risks

\footnotetext{
${ }^{6}$ In this framework, the assumption of prudent behavior can be extended to the fourth-order risk apportionment also known as temperance, and so on.
} 
because contemporaneous innovations in the marginal and conditional cumulative distributions or changes in downside and upside risks can readily be accounted for. Beyond the family of elliptical distributions, several other classes of bivariate random variables are PQD. For examples of such distributions, see Balakrishnan and Lai (2009) and Dionne et al. (2013).

Wright (1987) introduced the concept of expectation dependence which is a weaker definition of dependence than PQD.

\section{Definition A.2 If}

$$
\begin{aligned}
& F E D(\tilde{x} \mid y)=[E \tilde{x}-E(\tilde{x} \mid \tilde{y} \leq y)] \geq 0 \text { for all } y \in R \\
& \text { then } \tilde{x} \text { is positive first - degree expectation dependent on } \tilde{y} .
\end{aligned}
$$

The collection of all distributions $F$ satisfying Equation 25 is denoted $\mathcal{F}_{1}$. Similarly, $\tilde{x}$ is negative first-degree expectation dependent on $\tilde{y}$ if Equation 25 holds with the inequality sign reversed. The set of negative first-degree expectation dependent distributions is denoted $\mathcal{G}_{1}$.

As discussed in Wright (1987, p. 113), a straightforward interpretation of negative FED is as follows: "When we discover $\tilde{y}$ is small, in the precise sense that we are given the truncation $\tilde{y} \leq y$, our expectation of $\tilde{x}$ is revised upward." Note that FED is a weaker definition of dependence than quadrant dependence, but a stronger definition than correlation. This property entails that bivariate random variables that are positive (negative) quadrant dependent are also first-degree expectation dependent. However, positively (negatively) correlated random variables are not necessarily positive (negative) first-degree expectation dependent.

Building on a general concept of Nth-degree expectation dependence, Li (2011) suggests the following weaker definition of dependence.

\section{Definition A.3 If}

$$
\begin{aligned}
\operatorname{SED}(\tilde{x} \mid y) & =\int_{-\infty}^{y}[E \tilde{x}-E(\tilde{x} \mid \tilde{y} \leq t)] F_{y}(t) d t \\
& =\int_{-\infty}^{y} F E D(\tilde{x} \mid t) F_{y}(t) d t \geq 0 \text { for all } y
\end{aligned}
$$

then $\tilde{x}$ is positive second-degree expectation dependent on $\tilde{y}$.

The collection of all distributions $F$ satisfying Equation 26 is denoted $\mathcal{F}_{2}$. Similarly, $\tilde{x}$ is negative second-degree expectation dependent on $\tilde{y}$ if Equation 26 holds with the inequality sign reversed. The set of negative second-degree expectation dependent distributions is denoted $\mathcal{G}_{2}$. 
Obviously, $\mathcal{F}_{1} \subseteq \mathcal{F}_{2}$ and $\mathcal{G}_{1} \subseteq \mathcal{G}_{2}$ but the converse is not true. Since $\tilde{x}$ and $\tilde{y}$ are positively correlated when (Lehmann 1966, lemma 2)

$$
\begin{aligned}
\operatorname{cov}(\tilde{x}, \tilde{y}) & =\int_{-\infty}^{+\infty} \int_{-\infty}^{+\infty}\left[F(x, y)-F_{x}(x) F_{y}(y)\right] d x d y \\
& =\int_{-\infty}^{+\infty} F E D(\tilde{x} \mid t) F_{y}(t) d t \geq 0
\end{aligned}
$$

it follows that $\operatorname{cov}(\tilde{x}, \tilde{y}) \geq 0$ is a necessary condition for $(\tilde{x}, \tilde{y}) \in \mathcal{F}_{2}$ but the converse is not true. Thus, there are several bivariate random variables outside the elliptical or Gaussian families that are FED or SED, because all the positive quadrant dependent distributions are also FED and SED. The formulas in Equations (26) and (27) show that $\operatorname{cov}(\tilde{x}, \tilde{y})$ is the second central cross-moment of $\tilde{x}$ and $\tilde{y}$, whereas $\operatorname{SED}(\tilde{x} \mid y)$ is related to the second central lower partial cross-moment of $\tilde{x}$ and $\tilde{y}$. The latter measure of dependence can be interpreted as a metric of downside risk, computed as the average of squared deviations below a threshold.

\section{A2 Bond pricing with expectation dependence}

The valuation rule of an asset should solve the allocation problem of a typical investor. Let's consider a representative investor who can freely trade a risky bond with random payoff $\tilde{x}_{t+T}$ at a price $B_{t}^{T}$. This investor is endowed with a preference represented by a utility function $u(\bullet)$ defined over a state variable, namely, his level of consumption $c .^{7}$ Thus, the investor must decide how much of his wealth to allocate between the defaultable bond and consumption through time. The resulting pricing equation of a defaultable corporate bond with maturity $\mathrm{T}$, in its conditional form, writes

$$
B_{t}^{T}=E_{t}\left[\tilde{M}_{t+T} \tilde{x}_{t+T}\right]
$$

where $B_{t}^{T}$ is the corporate bond price at time $t, \tilde{M}_{t+T}$ is the pricing kernel, $\tilde{x}_{t+T}$ is the payoff of the corporate bond at time $t+T$.

The pricing kernel $\tilde{M}_{t+T}=M\left(\tilde{c}_{t+T}\right)=\beta \frac{u^{\prime}\left(\tilde{c}_{t+T}\right)}{u^{\prime}\left(c_{t}\right)}$, which depends on a random consumption at maturity, is the product of the subjective discount factor $(\beta)$ and the intertemporal marginal rate of substitution $\left(\frac{u^{\prime}\left(\tilde{c}_{t+T}\right)}{u^{\prime}\left(c_{t}\right)}\right)$.

\footnotetext{
${ }^{7}$ The historical variation of consumption through the business cycle is weak, possibly because of the availability of insurance programs including unemployment protection. Alternative state variables such as labor market indicators may be used for asset pricing, as they induce higher variability than consumption. For further discussions, see Lettau and Ludvigson (2001) and Santos and Veronesi (2006), among others.
} 
The risky bond payoff $\tilde{x}_{t+T}=1-\mathbb{I}_{[\tau \leq T]} L_{\tau, t+T}$ depends on the default time $(\tau)$, and the product $\widetilde{\mathcal{L}}_{\tau, t+T}=\mathbb{I}_{[\tau \leq T]} L_{t+T}(\tau)$ between the indicator function of default and the loss given default. The indicator function of default is a discrete variable which takes a value of 1 if $(\tau \leq T)$ and 0 otherwise. The loss given default $L_{\tau, t+T}$ is a continuous random proportion falling within the $(0,1)$ interval, and can be characterized by the Beta distribution. For simplicity, the loss given default is often assumed constant with a value set to its historical average level in common pricing formulas such as Equation 16. However, more realistic pricing rules should account for the randomness in $\widetilde{\mathcal{L}}_{\tau, t+T}$ which can be modelled as a mixed continuous-discrete distribution on $(0,1)$ with a probability mass at 0 for non-default occurrences. The zero-inflated Beta distribution is an example of such a distribution. The properties of the zero-inflated Beta distribution are discussed in Ospina and Ferrari (2010), among others.

Equation 28 can be rewritten in terms of covariance as

$$
\begin{aligned}
B_{t}^{T} & =\frac{E_{t}\left(\tilde{x}_{t+T}\right)}{1+R_{f}}+\beta \frac{\operatorname{cov}_{t}\left(u^{\prime}\left(\tilde{c}_{t+T}\right), \tilde{x}_{t+T}\right)}{u^{\prime}\left(c_{t}\right)} \\
& =\frac{1-E_{t}\left(\widetilde{\mathcal{L}}_{\tau, t+T}\right)}{1+R_{f}}-\beta \frac{\operatorname{cov}_{t}\left(u^{\prime}\left(\tilde{c}_{t+T}\right), \widetilde{\mathcal{L}}_{\tau, t+T}\right)}{u^{\prime}\left(c_{t}\right)}
\end{aligned}
$$

where $R_{f}=E_{t}\left(M_{t+T}\right)^{-1}-1$ is the net risk-free rate.

Equivalently, Equation 28 can be stated in terms of the bond return $1+\tilde{R}_{t+T}=\frac{\tilde{x}_{t+T}}{B_{t}^{T}}$ as

$$
\begin{aligned}
E_{t} \tilde{R}_{t+T}-R_{f} & =-\beta\left(1+R_{f}\right) \frac{\operatorname{cov}_{t}\left[u^{\prime}\left(\tilde{c}_{t+T}\right), \tilde{R}_{t+T}\right]}{u^{\prime}\left(c_{t}\right)} \\
& =-\frac{\operatorname{cov}_{t}\left[u^{\prime}\left(\tilde{c}_{t+T}\right), \tilde{R}_{t+T}\right]}{E_{t} u^{\prime}\left(\tilde{c}_{t+T}\right)}
\end{aligned}
$$

Huang and Huang (2012) calibrate the expected future cash flow $E_{t}\left(\tilde{x}_{t+T}\right)$ with historical levels and find that the covariance term is not large enough to match the (totality of) observed spreads based on various structural models of default.

We now generalize the pricing relation to higher-order risks and risk attitudes. Theorem 1 in Cuadras (2002) allows the following decomposition of the covariance

$$
\begin{aligned}
& \operatorname{cov}_{t}\left[u^{\prime}\left(\tilde{c}_{t+T}\right), \widetilde{\mathcal{L}}_{\tau, t+T}\right] \\
= & \int_{-\infty}^{+\infty} \int_{-\infty}^{+\infty}\left[F\left(c_{t+T}, \mathcal{L}_{\tau, t+T}\right)-F_{c_{t+T}}\left(c_{t+T}\right) F_{\mathcal{L}_{\tau, t+T}}\left(\mathcal{L}_{\tau, t+T}\right)\right] u^{\prime \prime}\left(c_{t+T}\right) d \mathcal{L}_{\tau, t+T} d c_{t+T} .
\end{aligned}
$$

From the following equality

$$
\int_{-\infty}^{+\infty}\left[F_{\mathcal{L}_{\tau, t+T}}\left(\mathcal{L}_{\tau, t+T} \mid \tilde{c}_{t+T} \leq c_{t+T}\right)-F_{\mathcal{L}_{\tau, t+T}}\left(\mathcal{L}_{\tau, t+T}\right)\right] d \mathcal{L}_{\tau, t+T}=E \tilde{\mathcal{L}}_{\tau, t+T}-E\left(\tilde{\mathcal{L}}_{\tau, t+T} \mid \tilde{c}_{t+T} \leq c_{t+T}\right)
$$


(see Lemma 1 in Tesfatsion 1976), we obtain

$$
\begin{aligned}
& \operatorname{cov}_{t}\left[u^{\prime}\left(\tilde{c}_{t+T}\right), \tilde{\mathcal{L}}_{\tau, t+T}\right] \\
= & \int_{-\infty}^{+\infty}\left[E \tilde{\mathcal{L}}_{\tau, t+T}-E\left(\tilde{\mathcal{L}}_{\tau, t+T} \mid \tilde{c}_{t+T} \leq c_{t+T}\right)\right] F_{c_{t+T}}\left(c_{t+T}\right) u^{\prime \prime}\left(c_{t+T}\right) d c_{t+T} \\
= & \int_{-\infty}^{+\infty} F E D\left(\tilde{\mathcal{L}}_{\tau, t+T} \mid c_{t+T}\right) u^{\prime \prime}\left(c_{t+T}\right) F_{c_{t+T}}\left(c_{t+T}\right) d c_{t+T},
\end{aligned}
$$

as stated in Theorem 3.1 of Wright (1987). To sign the covariance between marginal utility of consumption and the bond's payoff, we cannot use Stein's (1973) lemma since we do not assume joint normality. The equivalence between the sign of $\operatorname{cov}(f(x), y)$ and positive (or negative) FED for any monotone function $f(x)$ is given by Theorem 3.1 in Wright. Thus, the monotonicity of $u^{\prime}\left(c_{t+T}\right)$ allows the application of the theorem to get Equation 32 .

Using Equation 32 we can split the covariance in terms of FED and the investor's risk aversion. ${ }^{8}$ Thus, the pricing relation of Equation 29 becomes $^{9}$

$$
\begin{aligned}
B_{t}^{T}= & \underbrace{\frac{1-E_{t}\left(\widetilde{\mathcal{L}}_{\tau, t+T}\right)}{1+R_{f}}}_{\text {risk-free present value effect }} \\
& +\underbrace{\beta \int_{-\infty}^{+\infty} F E D\left(\widetilde{\mathcal{L}}_{\tau, t+T} \mid c_{t+T}\right) F_{c_{t+T}}\left(c_{t+T}\right)\left[-\frac{u^{\prime \prime}\left(c_{t+T}\right)}{u^{\prime}\left(c_{t}\right)}\right] d c_{t+T}}_{\text {first-degree expectation dependence effect }} \\
= & \frac{1-E_{t}\left(\widetilde{\mathcal{L}}_{\tau, t+T}\right)}{1+R_{f}} \\
& +\beta \int_{-\infty}^{+\infty} F E D\left(\widetilde{\mathcal{L}}_{\tau, t+T} \mid c_{t+T}\right) F_{c_{t+T}}\left(c_{t+T}\right) A R\left(c_{t+T}\right) M R S_{c_{t+T}, c_{t}} d c_{t+T},
\end{aligned}
$$

where $A R\left(c_{t+T}\right)=-\frac{u^{\prime \prime}\left(c_{t+T}\right)}{u^{\prime}\left(c_{t+T}\right)}$ is the Arrow-Pratt absolute risk aversion coefficient and $M R S_{c_{t+T}, c_{t}}=$ $\frac{u^{\prime}\left(c_{t+T}\right)}{u^{\prime}\left(c_{t}\right)}$ is the marginal rate of substitution between $c_{t+T}$ and $c_{t}$.

Equation 30 can also be rewritten as

$$
E_{t} \tilde{R}_{t+T}-R_{f}=\int_{-\infty}^{+\infty} \underbrace{F E D\left(\tilde{R}_{t+T} \mid c_{t+T}\right) F_{c_{t+T}}\left(c_{t+T}\right)}_{\text {consumption risk effect }} \underbrace{\left[-\frac{u^{\prime \prime}\left(c_{t+T}\right)}{E_{t} u^{\prime}\left(\tilde{c}_{t+T}\right)}\right]}_{\text {price of risk effect }} d c_{t+T} .
$$

Given that $R_{f}=\frac{1}{\beta} \frac{u^{\prime}\left(c_{t}\right)}{E_{t} u^{\prime}\left(\tilde{c}_{t+T}\right)}-1$, we get

$$
\begin{aligned}
& E_{t} \tilde{R}_{t+T}-R_{f} \\
= & \beta\left(1+R_{f}\right) \int_{-\infty}^{+\infty} F E D\left(\tilde{R}_{t+T} \mid c_{t+T}\right) F_{c_{t+T}}\left(c_{t+T}\right) A R\left(c_{t+T}\right) M R S_{c_{t+T}, c_{t}} d c_{t+T} .
\end{aligned}
$$

\footnotetext{
${ }^{8}$ Assuming a normal distribution for the pair $\left(\tilde{c}_{t+T}, \tilde{\mathcal{L}}_{\tau, t+T}\right)$, one can invoke Stein's lemma to rewrite $\operatorname{cov}_{t}\left[u^{\prime}\left(\tilde{c}_{t+T}\right), \tilde{\mathcal{L}}_{\tau, t+T}\right]$ as $\operatorname{cov}_{t}\left(\tilde{c}_{t+T}, \tilde{\mathcal{L}}_{\tau, t+T}\right) E_{t}\left(u^{\prime \prime}\left(\tilde{c}_{t+T}\right)\right)$.

${ }^{9}$ This representation also holds for any bounded $c_{t}$ and $c_{t+T}$.
} 
Equation 33 reveals that a risky bond price is made up of at least two components. The first term on the right-hand side of Equation 33, is the "risk-free present value effect." This effect depends on the expected return of the bond and the risk-free rate. The risk-free present value effect has the same sign as the expected return. This term captures the "direct" effect of the risk-free present expected return, which characterizes the bond price in a risk-neutral world. The second piece on the right-hand side of Equation 33 is termed as the first-degree expectation dependence effect or the "FED effect." This term involves the subjective discount factor, the expectation dependence between the random payoff and consumption, the Arrow-Pratt risk aversion coefficient, and the intertemporal marginal rate of substitution. The sign of the first-degree expectation dependence reflects whether the consumption and a risky bond's payoff tend "on average" to evolve in the same or opposite directions.

Equation 34 asserts that the credit spread can be assessed as the product of the quantity of consumption risk and the corresponding price of risk. Here, the quantity of consumption risk is measured by the FED of the credit spread with consumption. The price of risk is the Arrow-Pratt risk aversion coefficient times the intertemporal marginal rate of substitution.

Next, we extend the assumption of risk aversion and consider a risk-averse and prudent investor. Building on the pioneering work of Kimball (1990), Modica and Scarsini (2005) characterize prudence as the aversion towards any increase in downside risk. Note that prudence is often driven by motives such as precautionary saving. The key to our extension is to integrate the right-hand term of (32) by parts. Thus, we obtain

$$
\begin{aligned}
& \operatorname{cov}_{t}\left[u^{\prime}\left(\tilde{c}_{t+T}\right), \widetilde{\mathcal{L}}_{\tau, t+T}\right] \\
= & u^{\prime \prime}(+\infty) \operatorname{cov}_{t}\left(\widetilde{\mathcal{L}}_{\tau, t+T}, \tilde{c}_{t+T}\right)-\int_{-\infty}^{+\infty} \operatorname{SED}\left(\widetilde{\mathcal{L}}_{\tau, t+T} \mid c_{t+T}\right) u^{\prime \prime \prime}\left(c_{t+T}\right) d c_{t+T} .
\end{aligned}
$$

From Equation 27, we know that a negative $S E D\left(\widetilde{\mathcal{L}}_{\tau, t+T} \mid c_{t+T}\right)$ implies a negative $\operatorname{cov}\left(\widetilde{\mathcal{L}}_{\tau, t+T}, \tilde{c}_{t+T}\right)$ but the converse is not true. Hence, from Equation 36 we have $\operatorname{cov}_{t}\left(\widetilde{\mathcal{L}}_{\tau, t+T}, \tilde{c}_{t+T}\right) \leq 0$ is a necessary but not sufficient condition for $\operatorname{cov}_{t}\left[u^{\prime}\left(\tilde{c}_{t+T}\right), \widetilde{\mathcal{L}}_{\tau, t+T}\right] \geq 0$ for all $u^{\prime \prime} \leq 0$ and $u^{\prime \prime \prime} \geq 0$. With a positive SED function, prudence is also necessary. 
Equations 33 and 34 can be rewritten as

$$
\begin{aligned}
B_{t}^{T}= & \underbrace{\frac{1-E_{t}\left(\widetilde{\mathcal{L}}_{\tau, t+T}\right)}{1+R_{f}}}_{\text {risk-free present value effect }}+\underbrace{\beta \operatorname{cov}_{t}\left(\widetilde{\mathcal{L}}_{\tau, t+T}, \tilde{c}_{t+T}\right)\left[-\frac{u^{\prime \prime}(+\infty)}{u^{\prime}\left(c_{t}\right)}\right]}_{\text {covariance effect }} \\
+ & \underbrace{\beta \int_{-\infty}^{+\infty} S E D\left(\widetilde{\mathcal{L}}_{\tau, t+T} \mid c_{t+T}\right)\left[\frac{u^{\prime \prime \prime}\left(c_{t+T}\right)}{u^{\prime}\left(c_{t}\right)}\right] d c_{t+T}}_{\text {second-degree expectation dependence effect }}
\end{aligned}
$$

or

$$
\begin{aligned}
B_{t}^{T}= & \frac{1-E_{t}\left(\widetilde{\mathcal{L}}_{\tau, t+T}\right)}{1+R_{f}}+\beta \operatorname{cov}_{t}\left(\widetilde{\mathcal{L}}_{\tau, t+T}, \tilde{c}_{t+T}\right) A R(+\infty) M R S_{+\infty, c_{t}} \\
& +\beta \int_{-\infty}^{+\infty} S E D\left(\widetilde{\mathcal{L}}_{\tau, t+T} \mid c_{t+T}\right) A P\left(c_{t+T}\right) M R S_{c_{t+T}, c_{t}} d c_{t+T}
\end{aligned}
$$

where $A P\left(c_{t+T}\right)=\frac{u^{\prime \prime \prime}\left(c_{t+T}\right)}{u^{\prime}\left(c_{t+T}\right)}$ is the index of absolute prudence ${ }^{10}$, and

$$
\begin{aligned}
& E_{t} \tilde{R}_{t+T}-R_{f} \\
= & \underbrace{\operatorname{cov}\left(\tilde{R}_{t+T}, \tilde{c}_{t+T}\right)\left[-\frac{u^{\prime \prime}(+\infty)}{E_{t} u^{\prime}\left(\tilde{c}_{t+T}\right)}\right]}_{\text {consumption covariance effect }} \\
& +\underbrace{\int_{-\infty}^{+\infty} S E D\left(\tilde{R}_{t+T} \mid c_{t+T}\right) \frac{u^{\prime \prime \prime}\left(c_{t+T}\right)}{E_{t} u^{\prime}\left(\tilde{c}_{t+T}\right)} d c_{t+T}}_{\text {consumption second-degree expectation dependence effect }}
\end{aligned}
$$

or

$$
\begin{aligned}
& E_{t} \tilde{R}_{t+T}-R_{f} \\
= & \beta\left(1+R_{f}\right) \operatorname{cov}_{t}\left(\tilde{R}_{t+T}, \tilde{c}_{t+T}\right) A R(+\infty) M R S_{+\infty, c_{t}} \\
& +\beta\left(1+R_{f}\right) \int_{-\infty}^{+\infty} S E D\left(\tilde{R}_{t+T} \mid c_{t+T}\right) A P\left(c_{t+T}\right) M R S_{c_{t+T}, c_{t}} d c_{t+T} .
\end{aligned}
$$

Equation 37 states that positive correlation is only a necessary condition for all risk-averse and prudent agents to pay a lower bond price. Using only the covariance term of $\widetilde{\mathcal{L}}_{\tau, t+T}$ and $\tilde{c}_{t+T}$ induces a distortion in the pricing formula when the third derivative of the utility function is different from zero or when the utility function is not quadratic. The pricing condition in Equation 37 involves three terms. The first term on the right-hand side is identical to the one in Equation 33. The second term on the right-hand side is the "covariance effect." This term involves the subjective discount factor, the covariance of bond return and consumption, the Arrow-Pratt risk aversion

\footnotetext{
${ }^{10}$ Modica and Scarsini (2005) propose $\frac{u^{\prime \prime \prime}(x)}{u^{\prime}(x)}$ instead of $-\frac{u^{\prime \prime \prime}(x)}{u^{\prime \prime}(x)}$ (Kimball, 1990) as an alternative candidate to evaluate the intensity of prudence.
} 
coefficient, and the marginal rate of substitution. The third term on the right-hand side is called the second-degree expectation dependence effect or the "SED effect," which reflects how the seconddegree expectation dependence risk affects the bond price through the intensity of downside risk aversion. Equation 39 shows that a positive SED reinforces the positive covariance effect to obtain a positive risk premium. Ultimately, it provides a theoretical equilibrium argument to support the empirical findings of the asymmetric split normal credit model discussed in Section 3. Note that the proposed expectation dependence-based credit spread framework will be fitted to actual data in order to assess its empirical features.

The pricing Equation 40 can be easily extended to third-degree expectation dependence (quantity of risk) and temperance (price of risk) by iterating the integration by parts of Equation 36 . Thus, the proposed expectation dependence pricing framework can explicitly account for higherorder risks and risk behaviors in the valuation of risky bonds.

\section{B Construction of bond Specific and systematic illiquidity indices}

Standards on measuring bond illiquidity have shifted after corporate bond traders started reporting their Over-the-counter trades providing more accurate bond specific intra-daily trading data. Yet, traders still rely on common traditional rules on bond trading activities to define their first cut for liquid bond. For instance, when a bond is first issued it tends to trade frequently for at least a year then it starts trading less and almost disappears from the trading desk until it trades again few months before its maturity date. We also observe heavy message traffic from traders offering bid and ask quotes for those young bonds (Bloomberg bond trading system). Thus, we consider bond age as one of bond specific measures of illiquidity. As a bond ages it becomes more illiquid. A second filter used by traders and portfolio managers to identify liquid bonds on the fly is the par amount outstanding, referred to as the size of the bond. For instance, a bond with a size of US $\$ 500$ millions or more is likely to be liquid. As size increases with liquidity we consider the inverse size as an additional bond specific variable increasing with illiquidity. We also compute four more factors based on intra daily bond level trading activities. Specifically, we measure eight illiquidity variables as in Dick-Nielsen et al. (2012). We compute the bond daily price impact using the average between the standardized measures of the daily Amihud and the daily average holding period specific to a given bond. All daily measures are computed using a 21 business day rolling window. Each daily measure is standardized by subtracting it from its sample mean and dividing it by its sample standard deviation. We measure the sample mean and sample standard deviation using all bonds 
in our sample. Amihud measures the absolute price return relative to a one dollar amount of trade. It increases with illiquidity. The average holding period is the inverse of the turnover and refers to the ratio between the daily amount outstanding and the daily volume of the trade. The average holding period indicates how long it will take on average to trade a particular bond. The higher the average holding period of a bond the more illiquid it is. We measure the bid ask spread component using the average between standardized daily measures of Roll and Imputed Roundtrip Cost (IRC). Roll measures the implied bid/ask spread of a trade using the 2 times the square root of the negative covariance between successive price returns. In other words, when returns bounce in different directions they are likely to capture the bid/ask spread of the trade. The IRC is a more explicit measure of bid/ask spread where implicitly we identify the bid and ask prices in a roundtrip trade between at least a client and two traders. We also measure the liquidity risk component by taking the average between two measures of liquidity risk defined by taking the standard deviation of Roll and IRC over our 21 day rolling window. The illiquidity risk variables increase with the bond illiquidity. Finally, we measure the zero trade component using the average of standardized measures of bond zero trade and firm zero trade. Both measures compute the number of days a bond or its firm does not trade within a 21 business day window. Both measures increase with the illiquidity of the bond. We use the six bond level liquidity components to construct our bond level illiquidity index. To understand the dynamics of the six measures and how we would aggregate them to build our index we use support from the principal component analysis. Panel A-1 and Panel B-1 in Table B1 below report the eigenvalues of the six principal components corresponding to the factor analysis of our six bond level liquidity factors for AAA- and BBB-rated bonds respectively. The rst principal component explains respectively $51 \%$ and $43 \%$ of total dependence for AAA- and BBB-rated bonds. Panel A-2 and Panel B-2 report the eigenvectors corresponding to the six bond level liquidity components for AAA- and BBB- rated-bonds respectively. They indicate that the rst factor is fairly represented by an equally weighted average of the six bond level liquidity factors especially for the AAA-rated bonds. For BBB-rated bonds the age, the size and the zero trade measures are less important in the first principal component but become significant in the second principal component. We reconcile these results and use an equally weighted average of the six liquidity factors to construct two indices measuring bond specific liquidity for AAA- and BBB-rated bonds. The measure of the systematic liquidity index is straightforward. We first construct the same illiquidity indices for all rated bonds in our sample. Specifically, we includes bonds rated from AAA to BB, where the BB group of bonds includes all bonds rated BB or below. To obtain our 
systematic illiquidity factor we aggregate all illiquidity indices in our bond universe.

This table reports summary statistics on the principal component analysis applied to liquidity components of straight xed-coupon corporate bonds in the industrial sector. We report principal components and eigenvectors results in Panel A-1 and A-2 for AAA rated-bonds and Panel B-1 and B-2 for BBB rated-bonds. The covered period ranges from January 2008 to December 2014. 
Table B1: Construction of illiquidity indexes (Jan. 2008 to Dec. 2014)

Panel A-1: Principal components for AAA-rated bonds

\begin{tabular}{lcccccc}
\hline Rank & Eigenvalue & Difference & Proportion & Cumulative & & \\
\hline $1^{\text {st }}$ comp. & 3.027 & 1.765 & 0.505 & 0.510 & & \\
$2^{\text {nd }}$ comp. & 1.261 & 0.470 & 0.210 & 0.715 & & \\
$3^{\text {rd }}$ comp. & 0.791 & 0.318 & 0.132 & 0.847 & & \\
$4^{\text {th }}$ comp. & 0.472 & 0.155 & 0.079 & 0.925 & & \\
$5^{\text {th }}$ comp. & 0.316 & 0.185 & 0.053 & 0.978 & & \\
$6^{\text {th }}$ comp. & 0.131 & & 0.022 & 1.000 & & \\
\hline Panel A-2: Eigenvectors for AAA-rated bonds & AA & & & \\
\hline Variables & $1^{\text {st }}$ comp. & $2^{\text {nd }}$ comp. & $3^{\text {rd }}$ comp. & $4^{\text {th }}$ comp. & $5^{\text {th }}$ comp. & $6^{\text {th }}$ comp. \\
\hline Age & -0.421 & 0.010 & -0.481 & 0.766 & -0.059 & 0.001 \\
Inverse size & -0.335 & 0.222 & 0.814 & 0.343 & 0.240 & 0.015 \\
Price impact & 0.450 & -0.279 & 0.299 & 0.388 & -0.668 & -0.180 \\
Bid/Ask & 0.452 & 0.452 & -0.113 & 0.199 & 0.354 & -0.642 \\
Liquidity & 0.479 & 0.400 & -0.046 & 0.235 & 0.071 & 0.740 \\
Zero trade & 0.270 & -0.713 & 0.031 & 0.224 & 0.601 & 0.083 \\
\hline
\end{tabular}

Panel B-1: Principal components for BBB-rated bonds

\begin{tabular}{lcccc}
\hline Rank & Eigenvalue & Difference & Proportion & Cumulative \\
\hline $1^{\text {st }}$ comp. & 2.569 & 1.096 & 0.430 & 0.430 \\
$2^{\text {nd }}$ comp. & 1.473 & 0.052 & 0.245 & 0.674 \\
$3^{\text {rd }}$ comp. & 0.957 & 0.306 & 0.159 & 0.833 \\
$4^{\text {th }}$ comp. & 0.651 & 0.410 & 0.108 & 0.942 \\
$5^{\text {th }}$ comp. & 0.241 & 0.133 & 0.040 & 0.982 \\
$6^{\text {th }}$ comp. & 0.107 & & 0.018 & 1.000 \\
\hline
\end{tabular}

Panel B-2: Eigenvectors for BBB-rated bonds

\begin{tabular}{lcccccc}
\hline Variables & $1^{\text {st }}$ comp. & $2^{\text {nd }}$ comp. & $3^{\text {rd }}$ comp. & $4^{\text {th }}$ comp. & $5^{\text {th }}$ comp. & $6^{\text {th }}$ comp. \\
\hline Age & 0.140 & 0.397 & 0.823 & 0.298 & -0.236 & -0.041 \\
Inverse size & -0.083 & -0.642 & 0.028 & 0.755 & -0.084 & 0.041 \\
Price impact & 0.514 & 0.137 & -0.040 & 0.113 & -0.724 & -0.123 \\
Bid/Ask & 0.585 & -0.089 & 0.030 & 0.077 & 0.499 & -0.627 \\
Liquidity & 0.594 & -0.086 & 0.059 & -0.024 & 0.240 & 0.759 \\
Zero trade & -0.117 & 0.628 & -0.390 & 0.566 & 0.324 & 0.109 \\
\hline
\end{tabular}

This table describes the eigenvalues and eigenvectors for the construction of illiquidity indexes based on principal component (denoted by comp.) analysis . 